\title{
LA FUNCIÓN ECONÓMICA DE LA CONTRATACIÓN MASIVA
}

\author{
REYLER YUlFo RODRÍGUEZ CHÁVEZ*
}

\begin{abstract}
Resumen
Mediante el presente ensayo se aborda el tema de la contratación masiva desde la perspectiva del análisis económico del derecho (AED), con la finalidad de delinear las pautas que fundamentan la función económica que viene cumpliendo esta forma de contratación dentro del actual escenario de intercambios económicos, caracterizado por la presencia de dos factores con especiales distinciones, la sociedad de masas y la producción masiva de bienes y servicios. Entre ellos, es la contratación masiva a través de sus diversas formas, como los contratos por adhesión y las cláusulas generales de contratación, la que permite entrelazar las transacciones mercantiles consolidando vínculos jurídicos entre los empresarios a cargo de la oferta de los bienes y servicios y los consumidores demandantes de aquellos bienes y servicios. La contratación masiva, a la vez que dota de seguridad jurídica a aquellas relaciones jurídicas de intercambio masivo, las hace rápidas y eficientes, acorde a las exigencias del mercado. Es por ello, que esta forma de contratación no solo es un "medio fin" que permite entrelazar y constituir ambos polos (empresarios y consumidores) sino que además, al consolidar el andamiajejurídico del contrato permite reducir costos de transacción en tiempo, dinero, esfuerzo. De allí que la contratación masiva también constituya un "fin en sí misma".
\end{abstract}

Palabras clave: Contratación masiva - Función económica de la contratación masiva - Análisis económico del derecho - Producción masiva de bienes y servicios.

\begin{abstract}
This article addresses the issue of mass contracts from a perspective of law and economics, with the aim of providing guidelines on the economic function of this form of contracts within the present context of economic exchanges, characterized by the presence of two distinct factors, mass society and the mass production of goods and services. Among these, it is mass contracting, in its different forms, such as the standard form contract (contract of adhesion) and the general contracting articles that allow the articulation of trade operations thereby consolidating legal bonds between the businessmen in charge of supplying goods and services and the consumers who demand them. At the same time, mass contracting not only provides legal security to those mass contracting relations but also makes them efficient and effective according to the market requirements. Thus, this form of contracting is not solely an "objective/means" that links both poles (businessmen and consumers) but also enables the reduction of transactional costs in time, money and effort, thereby constituting a means to an end.
\end{abstract}

\footnotetext{
* Juez de Paz Letrado Titular de la Corte Superior de Justicia de Lima Norte-Poder Judicial del Perú.
} 
Reyler Yulfo Rodríguez Chávez - La función económica de la contratación masiva

Key words: Mass Contracts - Economic Function of Standard Form Contracts - Economic analysis of the law - Mass production of goods and services.

\section{Sumario:}

1. Introducción. 2. Génesis de la contratación masiva. 2.1. El advenimiento de la sociedad de las masas. 2.2. Los fenómenos masivos. 2.2.1. El fenómeno de la producción masiva de bienes y servicios. 2.2.2. La masificación del intercambio económico: el tráfico masivo. 2.3. Génesis de la contratación masiva. 3. La contratación masiva. 3.1. Definición de contratación masiva. 3.2. Características de la contratación masiva. 3.2.1. Falta o limitación de la negociación. 3.2.2. Despersonalización de las relaciones contractuales. 3.2.3. Elaboración en forma masiva o estandarizada. 3.3. Funciones de la contratación masiva. 4. El análisis económico del derecho contractuaL. 4.1. El derecho y la economía. 4.2 El análisis económico del derecho (AED). 4.3. El análisis económico del contrato. 5. La función económica de la contratación masiva. 5.1. El principio de eficiencia contractual. 5.2. El principio de rapidez contractual. 5.3. El principio de economía contractual. 5.3.1. El factor tiempo en la contratación masiva. 5.3.2. El factor dinero en la contratación masiva. 5.3.3. El factor esfuerzo en la contratación masiva. 5.4. El principio de simplificación contractual. 5.5. La función económica de la contratación masiva como fin en sí misma. 6. Conclusiones.

\section{INTRODUCCIÓN}

No pasa por desapercibido en estos tiempos, la presencia cada vez mas vertiginosa y generalizada de lo que autores como Atilio Aníbal Alterini denominaron "formas modernas de contratación", como lo es sin duda alguna la contratación masiva o en masa. Aunque debemos hacer referencia que estas formas de contratación tienen su origen en las etapas de transformación y cambio que han venido experimentando las sociedades como producto de los avances científicos, tecnológicos y demográficos, con la consecuente implantación y auge del modelo económico capitalista, que actualmente se nos presenta con ciertos matices, como una economía social de mercado como es en el caso peruano.

Estos factores, generan el fenómeno denominado "sociedad de masas", con la consiguiente pérdida del individualismo de las personas que la componen, quienes simplemente son consideradas como un conjunto uniforme, un bloque humano fácilmente manipulable por los medios de comunicación, sobre todo en el ámbito económico en donde se produce lo que se conoce como el consumo masivo de bienes y servicios para satisfacer las múltiples necesidades de los individuos que forman parte de las masas y que adquieren la calidad de consumidores. 
Es aquí donde tienen lugar de manera muy peculiar las relaciones de intercambio masivo entre éstos y aquellos que generan bienes o servicios en forma estandarizada o en serie, relaciones que son canalizadas y dotadas de vinculación jurídica a través de los contratos masivos.

Es así que la contratación masiva, indudablemente obedece a las necesidades del tráfico masivo, es decir, de que frente a la producción en serie o en masa de bienes y servicios, corresponda la presencia de un instrumento capaz de canalizar en forma adecuada, con rapidez y eficiencia, la adquisición de estos bienes y servicios y; la mejor forma de lograr tal objetivo ha sido mediante la contratación masiva. Pues por un lado presenta la ventaja de permitir la celebración casi inmediata de innumerables contratos, evitando de esta manera la posible existencia de una "carga contractual", y por otro, evita que la existencia de costos excesivos en las transacciones hagan inviable e inaccesible para las partes la contratación.

Pese a que estos contratos son duramente criticados por el hecho de que eliminan, de manera total o parcial, la capacidad de negociación de una de las partes del contrato, a la que se le ha denominado la parte débil o débil contractual, pues nos hallamos ante contratos cuyos esquemas son predispuestos unilateralmente, pretendemos con el presente ensayo resaltar la gran importancia y la función trascendental que la contratación masiva viene cumpliendo para el derecho contractual y el tráfico económico.

Precisamente nos interesa describir los elementos que hacen que esta forma de contratación configure una función económica peculiar y complementaria a la función de contrato tradicional, acorde a las condiciones que exige el tráfico masivo.

\section{GÉNESIS DE LA CONTRATACIÓN MASIVA}

\subsection{El advenimiento de la sociedad de las masas}

A fines del siglo XIX y durante la primera mitad del siglo XX, a la par del desarrollo industrial con la invención de sofisticados inventos y el descubrimiento de nuevas fuentes de energía, se desarrollaba rápidamente un fenómeno que entraría a calar en las esferas mundiales, el aumento vertiginoso de la población y con ello el aumento de las necesidades de lo que más adelante se denominaría "la sociedad de masas".

Este hecho, fue en su momento objeto de numerosos estudios a fin de entender su verdadera naturaleza e implicancias, de forma que incluso Diez Picazo 
llegó a considerarlo como "uno de los fenómenos más espectaculares e importantes del acontecer histórico en los tiempos modernos" y además como la "causa evidente de transformaciones sociales" 1 .

Tal fue el asombro y las diversas reacciones que provocó el aumento demográfico de la población que incluso Ortega y Gasset llegó a considerarlo como "la rebelión de las masas" dado que su aparición alteró el curso de las relaciones en las sociedades de aquél entonces ${ }^{2}$.

Pero cuál es la idea que se tiene de la "sociedad de masas". Philipp Lersch señala que el término "masa" debe entenderse como "pura cantidad, una acumulación o conglomerado sin trabazón interna y sin forma externa, implica la homogeneidad de sus componentes o, cuando menos, la insignificancia de las diferencias que pudieran existir" 3 .

Trasladando el significado del término masa al de sociedad, el resultado preliminar que tendremos en frente es un conjunto o conglomerado de seres humanos reunidos bajo determinadas características que conforman un ente dinámico -las masas- que constituye el escenario en el cual tienen lugar un conjunto de interrelaciones también masivas protagonizadas por lo que se denominó en su momento el "hombre-masa" 4 .

En base a las características descritas, podemos ensayar una definición de lo que actualmente constituye una sociedad de masas o sociedad masiva, entendiéndola como aquél "ente dinámico" conformado por un conglomerado de individuos que se interrelacionan constantemente en función a los mismos factores -cuantitativos y cualitativos-, estableciéndose entre ellos una aparente uniformidad. Al interior de las masas, las relaciones se suscitan en total despersonalización y anonimato y es más, el cúmulo de personas

1 Diez PICAZO, Luis. Derecho y Masificación Social. Tecnología y Derecho Privado. Madrid: Editorial Civitas, 1979, p. 19.

2 Ortega Y Gasset, José. La Rebelión de las Masas. Primera edición. Lima: Editorial Universo, 1975, p. 48. El autor citado describía así este acontecimiento: "sencillísima de enunciar, aunque no de analizar, yo la denomino el hecho de la aglomeración, del "lleno", "la muchedumbre, de pronto, se ha hecho visible, se ha instalado en los lugares preferentes de la sociedad. Antes, si existía, pasaba inadvertida, ocupaba el fondo del escenario social; ahora se ha adelantado a las baterías, es ella el personaje principal. Ya no hay protagonistas: sólo hay coro" (Íbid., p. 49).

3 Citado por: Soto CoAguila, Carlos Alberto. «La transformación del contrato: del contrato negociado al contrato predispuesto». En: Instituciones de Derecho Privado. Contratación Contemporánea (Alterini, Atilio, De los Mozos, José Luis y Soto Coaguila, Carlos: Directores). Bogotá: Temis y Palestra Editores. Tomo I, 2000, p. 372.

4 El término "hombre-masa" apareció en la obra "La Rebelión de las Masas" de José Ortega y Gasset publicada en 1930. Fue utilizado para describir aquél hombre que no se diferenciaba de los demás, así como el comportamiento y las características singulares que presentaba este personaje como protagonista principal de las sociedades masivas o masificadas en pleno surgimiento. 
masificadas determina los parámetros en base a los cuales el individuo-masa debe asimilar su forma de vida.

\subsection{Los fenómenos masivos}

La presencia y desarrollo de la sociedad de masas influyó en el curso de toda la humanidad, pues todo lo que hasta ese entonces permanecía sujeto a determinados procedimientos, cambiaría drásticamente para seguir el curso que imponía la masificación universal. De modo que los aspectos más diversos de la vida que hasta ese entonces se tenían, tuvieron que adecuar sus estructuras para hacer frente a las exigencias de la sociedad de masas con todas las consecuencias que ello implicaba.

Es así que, durante esta fase de expansión de las masas hacia los diferentes sectores del mundo contemporáneo, se originan los llamados fenómenos masivos que como anota Diez Picazo no son otra cosa que "todos aquellos donde intervienen masas de personas y en los que se traban lógicamente relaciones masivas" ${ }^{5}$, fenómenos caracterizados por la despersonalización y de anonimato de las relaciones sociales.

Si bien estos fenómenos masivos tuvieron un carácter eminentemente social, pronto dejarían de ser hechos distanciados del ámbito jurídico. Por el contrario, hoy en día estos fenómenos masivos son fuente de problemas con significativa repercusión en el Derecho. Ya no son lo que Diez Picazo denominaba como problemas de "infraderecho" o "subderecho", sino más bien actualmente se formulan como un problema de dimensiones "macro jurídicas" 6 .

Dentro de estos fenómenos, nos interesa particularmente el fenómeno de la producción masiva de bienes y servicios, para entender su trascendencia la contratación masiva.

\subsubsection{El fenómeno de la producción masiva de bienes y servicios}

Como complemento del bloque humano conformado por la sociedad de masas, se desarrolló vertiginosamente la producción, gracias sobre todo a los avances en la ciencia y la tecnología. Estos nuevos protagonistas, conformaron el elemento necesario, preciso y justo para que la insuficiente y precaria empresa

5 Diez PICAZO, Luis. Derecho y Masificación Social. Tecnología y Derecho Privado. Op. Cit., p. 25.

6 Vallet De Goytisolo había advertido la trascendencia que tendrían los fenómenos masivos, para ello trató de estudiar las interrelaciones entre el Derecho y la sociedad de masas, llegando incluso a denominar "Derecho de Masas" a aquellas relaciones o efectos que ocurrían en el Derecho a consecuencia de la masificación social, así lo dejó sentado en su obra “Sociedad de Masas y Derecho" publicada en 1968. 
o taller, guiada en su mayoría por maquinaria a base de energía hidráulica, eólica o simplemente por la fuerza humana, pudieran abastecer mediante un proceso sofisticado de producción de bienes y servicios, la enorme demanda que exigían los actores de las masas.

Este aparente "feliz resultado de acoplamiento" completado por el engranaje de la producción, fue en su momento expresión de un complejo pero interesante proceso de transformación, donde la conjugación de una serie de elementos influidos por la ciencia y la tecnología, terminarían por afectar a la producción de bienes y servicios permitiendo así su evolución.

E. Moore describe que el empleo de la ciencia en la producción se manifestó principalmente en tres formas: "mayor complejidad y coordinación de la producción semiautomática (a máquina); incremento e intensificación de la producción mediante un dominio cada vez mayor de la energía mecánica; y multiplicación y estandarización de los productos industriales, con aumento en la variedad y en la cantidad de los artículos de consumo"7.

En este contexto, surge en primer término una relación "hombre-máquina", cuya representación más sofisticada es la organización industrial. La antigua relación "hombre-herramienta" que equivalía al pequeño "taller", ahora se ha convertido en una relación del hombre con la máquina, siendo su expresión principal la fábrica y la organización empresarial de la gran industria.

El punto central de este proceso evolutivo como destaca Drucker es que casi de un día para otro, "de la noche a la mañana", la producción a base del trabajo artesanal, pasó a basarse en las bondades que ofrecía la tecnología ${ }^{8}$.

Este hecho no escaparía al pensamiento de Carlos Marx, para quien la aparición de la fábrica en aquel periodo se caracterizó por constituir "un enorme autómata compuesto de numerosos órganos mecánicos e intelectuales -máquinas y obreros- que obran al unísono y sin interrupción para producir un mismo objeto, subordinados todos estos órganos a una potencia motriz que se mueve por sí misma" ${ }^{9}$.

\footnotetext{
MOORE, E. «El desarrollo de la industria moderna». En: Antología. De la Sociedad Tradicional a la Sociedad de las Masas. Graciarena, Jorge y SAutu, Ruth: Directores. Bs. As.: Editorial J.M. Álvarez, 1964, p. 270.

8 DruCKer, Peter F. La Sociedad Post Capitalista. Título original en inglés: "Post-Capitalist Society". Bogotá: Grupo Editorial Norma, 1994, p. 32.

9 MARX, Carlos. EL Capital. Lima: Editorial Mercurio, 1997, p. 100. Marx advierte además que la máquina, punto de partida de la revolución industrial, reemplaza ventajosamente al operario, quien sólo maneja una herramienta; mientras la máquina trabaja a la vez muchos utensilios semejantes y actúa con el impulso de una sola fuerza, sea cual sea quien la genere (Ídem, p. 109).
} 
Aparece así la gran industria, impulsada por nuevas fuentes de energía. El petróleo y la electricidad en reemplazo del carbón y el vapor. Las tradicionales formas de producción de bienes y servicios en talleres reducidos, a lo artesanal, con una producción limitada de artículos, son abandonadas para dar paso a la producción masiva o en serie de bienes y servicios.

Un nuevo agente se hace presente el escenario, la empresa, que gracias a su especialización, organización y el apoyo en la tecnología, lleva la batuta y el ritmo de la producción masiva de bienes y servicios. El empleo de la máquina por la empresa y en segundo término, la organización y distribución especializada del trabajo serían determinantes para alcanzar esta súper producción. Como destaca Fromm, los hombres "trabajan juntos a un ritmo que señalan los expertos, con métodos que formulan lo expertos, ni con demasiada rapidez, ni con demasiada lentitud, pero juntos; cada uno forma parte del todo" ${ }^{\prime \prime}$.

Surge así una nueva relación "empresa-máquina". Pues la compleja pero eficiente organización empresarial permitió según Vallespinos, que hoy en día sea posible "obtener determinados bienes-servicios mediante el simple hecho de apretar un botón, tirar de una palanca, oprimir una tecla"11. Pues debido a un conjunto organizado de elementos: máquinas equipadas a son de la tecnología, organización empresarial y la división y especialización del trabajo, se pudo aumentar la producción a gran escala de bienes y servicios. Se crea una tendencia en la forma de producción hacia la uniformidad de los artículos, los bienes y servicios producidos en masa, en forma estandarizada.

La empresa tiene desde ya una sola finalidad: producir por miles bienes y servicios acorde a lo requerido por las masas. Para Delfino Cazet la empresa cumple un rol esencial que es "el cumplimiento de operaciones sucesivas de la misma especie. Se está entonces ante la industria que produce y vende el mismo producto, la empresa que actúa entre oferta y demanda por medio de

\footnotetext{
10 Fromm, Erich. «La sociedad del siglo XX: cambios caracterológicos, sociales y económicos». En: Antología De la Sociedad Tradicional a la Sociedad de las Masas. Op. Cit., p. 379. Este mismo autor agrega lo siguiente: El cambio más manifiesto del siglo XIX al XX, es el de la técnica, el mayor uso de la máquina a vapor, del motor de combustión interna, de la electricidad, y el comienzo del empleo de la energía atómica. El proceso se caracteriza por la creciente sustitución del trabajo manual por el trabajo mecánico, y además por la sustitución de la inteligencia humana por la inteligencia de las máquinas. Mientras en 1850, el hombre proporcionaba 15 por ciento de la energía de trabajo, los animales 79 por ciento y las máquinas el 6 por ciento, la proporción en 1960 será de 3 por ciento, el 1 por ciento y el 96 por ciento respectivamente. (Ídem. p. 376).

11 Vallespinos, Carlos Gustavo. El Contrato por Adhesión a Cláusulas Generales. Bs. As.: Editorial Universidad, p. 186.
} 
iguales bienes y servicios. Ello tiene un único marco posible: uniformidad en la producción o circulación de bienes o servicios, estandarización productiva"12.

De manera que una pertinente y adecuada combinación de factores reflejaron un incremento importante en la producción y con ello se logró corresponder a la necesidad de la sociedad de masas por el consumo de bienes y servicios. Surge entonces el "acoplamiento" entre la necesidad masiva de bienes y servicios que emana de la sociedad de masas, y la producción masiva de aquellos por parte de la empresa.

Sin embargo, la masificación no solo afectó a la manera de producir los bienes y servicios por parte de la empresa sino también, repercutiría en la otra cara de la relación, los consumidores de tales bienes y servicios, activos integrantes de la sociedad de masas.

Antes del desarrollo tecnológico, durante "la primera ola" existía un protagonista en la sociedad, lo que Toffler llamó "prosumista" es decir aquellas personas que consumían lo que ellas mismas producían, nos dice Toffler que no eran ni productores ni consumidores. Luego, con los avances científicos y la aparición de la industria con fuentes de energía diferentes a la actividad humana, como el carbón y el vapor, se consolida una nueva relación, la de "productor a consumidor". Quienes producen ya no solo se dedican a consumir lo producido, sino que existe un exceso en la producción de artículos y que sale de sus esferas de consumo para ser intercambiado en el mercado por un sector de consumidores, por un público expectante de dichos bienes y servicios producidos. Había llegado la era de "la segunda ola"13.

Así entonces, la masificación logra establecer claramente las esferas de actuación de los protagonistas de las relaciones masivas, pues como señala Vega Mere, "se acentuó la diferencia de roles entre los productores y los consumidores. Aquéllos producen, éstos consumen. Aquéllos deben crear necesidades de toda índole, éstos deben consumir todo cuanto se ofrezca en el mercado. Los industriales hacen uso de los procedimientos más adecuados para fomentar y masificar el consumo: más clientes, más consumo por cada cliente"14.

12 Citado por: RezzóniCo, Juan Carlos. Contratos con Cláusulas Predispuestas. Condiciones Negociales Generales. Bs. As.: Editorial Astrea, 1987, p. 9-10.

${ }_{13}$ TOFFLER, Alvin. La Tercera Ola. Título original: "The Third Wave". Traducida por: Adolfo Martín, Plaza y Juanes Editores, Undécima edición, España, 1995, p. 343. Toffler alcanza que la revolución industrial introdujo una "cuña" que separó estas dos funciones y con ello se dio nacimiento a los denominados productores y consumidores.

14 Vega Mere, Yuri. Contratos de Consumo. Consideraciones Preliminares Sistemáticas a Favor de su Construcción Dogmática. Lima: Editorial Grijley, 2001, p. 32. 


\subsubsection{La masificación del intercambio económico: el "tráfico masivo"}

La masificación de la sociedad aunada a la producción masiva de bienes y servicios reflejó un aumento considerable de las relaciones de intercambio dentro del mercado. El tráfico económico que hasta entonces circulaba con relativa calma entre productores y consumidores, tendría que hacer frente a estos factores que lo convertirían también en un "tráfico masivo"15. Había que estar acorde a los acontecimientos que se venían originando en el mundo contemporáneo. El intercambio de bienes y servicios y su consumo por parte de las masas, se había masificado.

Inicialmente existió una correlación casi equitativa, un tráfico natural y más o menos homogéneo de que a igual producción de bienes y servicios correspondía igual consumo de los mismos -lográndose un binomio eficiente para la asignación de los recursos-. Sin embargo, la diversificación de la empresa y su especialización en la producción, determinarían el surgimiento de una nueva situación, ya no de armonía y de correspondencia, sino más bien de desequilibrio: la producción masiva había rebalsado la capacidad de consumo en ciertos campos.

Entraba en escena un tráfico artificial, caracterizado la existencia de un excedente de bienes y servicios en relación a la necesidad de su consumo por parte de los consumidores, done se recurre a la publicidad y el marketing para disminuir la brecha que se había creado, para generar mediante técnicas apropiadas, el consumo restante y agotar así el "stock" de todos bienes y servicios producidos "artificialmente". Se generan nuevos bienes y servicios, inicialmente sin un grupo de consumo definido y suficiente como para agotarlos, para luego generar artificialmente este consumo a través de la publicidad y del marketing ${ }^{16}$.

Pero el asunto no se agotó con el hecho de utilizar a la publicidad y al marketing para autogenerar ese "consumo faltante" que originalmente se había hecho

\footnotetext{
15 Diez Picazo describía este hecho señalando que la evolución económica y social de nuestro tiempo se ha visto condicionada merced a la dinámica interna del capitalismo por el fenómeno de la producción en masa y, por ello mismo, se ha visto forzada a una ampliación de la masa de consumidores, que determina un ensanchamiento del número de personas que aspiran a adquirir o disfrutar de los bienes y servicios que las grandes empresas proporcionan. Este hecho ha determinado un tráfico económico, cada vez más acelerado, que se ha ido convirtiendo en lo que rigurosamente puede llamarse un "tráfico en masa". (DiEZ PICAZO, Luis. Derecho y Masificación Social. Tecnología y Derecho Privado. Op. Cit., p. 42).

16 Esta circunstancia ya había sido descrita con precisión por De La Puente, quien afirmaba que muchas veces la verdadera necesidad de consumo por el público coincide con la provisión empresarial de bienes y servicios, de tal manera que el tráfico se realiza naturalmente. Otras, la producción de bienes y servicios supera la necesidad de consumo, por lo cual se recurre a fomentar, aunque sea artificialmente, esta necesidad. Surge la utilización de la publicidad como medio de influir sobre el pensamiento del público. (DE LA PUENTE Y LAVALLE, Manuel. El Contrato en General. . Tomo I. Lima: Palestra Editores, 2001, pp. 686-687).
} 
evidente, sino que se comenzó a "crear el consumo". Así lo señala Soto Coaguila cuando manifiesta que "la necesidad de que esta sociedad de masas adquiera o consuma bienes y servicios, de una u otra manera se multiplica. Objetivo de que así sea, es tarea de los productores; y la creación de estas necesidades se debe a la publicidad que juega un rol importante en este fenómeno"17.

A la luz de estos hechos, se perfecciona el anonimato de la sociedad de masas que se hace extensivo al consumo masivo. Ahora lo que importa es el individuo pero como "dato estadístico", como la principal herramienta donde ejerce y despliega toda su actividad el marketing y la publicidad para proyectar cual será la capacidad de respuesta, en términos de consumo, del hombre-masa respecto a determinado bien o servicio que esté listo para ser lanzado al mercado. Aparece como destaca Rezzónico, el "cliente abstracto" identificado por lo general por el "número de cliente", que es un "dato precioso" para ser colocado dentro del engranaje organizado por las computadoras ${ }^{18}$.

El hombre-masa es considerado pues como potencial agente de consumo, traducido en cifras manipulables a petición de los entes productivos. Si no existe necesidad, se la crea. Pues lo que las empresas necesitan como anota Fromm, son "hombres que cooperen sin razonamiento en grandes grupos, que deseen consumir cada vez más, y cuyos gustos estén estandarizados y fácilmente puedan ser influidos y previstos"19.

Para este mismo autor, el hombre contemporáneo presenta dos características singulares. Por un lado "el consumismo". El hombre consume todo cuanto el mundo produce, éste constituye "su gran mamadera" y concluye indicando figurativamente que el hombre se ha convertido en "lactante", "eternamente expectante y eternamente frustrado". La otra cualidad es la "enajenación", pues el hombre "se siente así mismo como extraño", disociado de sí mismo, ya no es amo de sus propios actos sino que éstos "se han convertido en amos suyos"20.

\footnotetext{
17 Soto Coaguila, Carlos Alberto. «La contratación masiva y la crisis de la teoría clásica del contrato». En: El Contrato en una Economía de Mercado. Trujillo: Editorial Normas Legales, 2004, p. 145. Sobre el asunto Diez Picazo se pronuncia señalando que la empresa hoy en día se ve en la necesidad de realizar una producción masiva a base de un número probable de clientes que serán "captados" a través del marketing y la publicidad, a los que considera como "fenómenos muy singularizados", Véase: Diez PICAzO, Luis. Fundamentos de Derecho Civil Patrimonial. Volumen primero. Quinta Edición. Madrid: Editorial Civitas, 1996, pp. 130-131.

18 ReZzónICO, Juan Carlos. Op. Cit., p. 6.

19 Fromm, Erich. «La sociedad del siglo XX: cambios caracterológicos, sociales y económicos». Op. Cit., 379. Este mismo autor señala que todo el mundo es incitado a comprar todo lo que puede aún antes de haber ahorrado lo suficiente para pagar sus compras. La publicidad y todos los demás medios de presión psicológica estimulan poderosamente la necesidad de consumo mayor (Ídem, p. 378).

${ }^{20}$ Citado por: Rezzónico, Juan Carlos. Op. Cit., p. 6-7.
} 
Entonces, el tráfico económico a la vez que se masifica, también se torna complejo. La circulación de la producción a gran escala o en serie no solo se produce espontáneamente, sino que ahora es generada artificialmente. El protagonista principal de tales intercambios, el hombre masificado, es manipulado para que consciente o inconscientemente adquiera aquellos productos en cuya elaboración y lanzamiento al mercado se emplearon estrategias de marketing y publicidad para lograr una respuesta instantánea de consumo. Estas relaciones conforman el tráfico económico masivo.

\subsection{Génesis de la contratación masiva}

La producción masiva de bienes y servicios aunada a las necesidades de la sociedad de masas que confluían en un acelerado tráfico económico, requerían que el Derecho Contractual cuente con un instrumento igual de ágil y eficiente, con la capacidad de viabilizar relaciones masivas de intercambio. En términos de Eorzi, "la producción en masa ha dado origen a la uniformidad tecnológica y esta última a la uniformidad contractual"21. Para Vallespinos los contratos en masa no son sino una consecuencia de la atomización del sujeto, es decir de la masificación social, lo que hace que las relaciones contractuales comiencen a manifestarse por medio de un "tipo contractual" o de un "contrato de masas"22.

Surge entonces, un mecanismo de intercambio, una nueva estructura de contrato que partiendo de las estructuras clásicas también se masifica, se adecua a las expectativas demandadas por el tráfico masivo. Aparece el contrato masivo, en serie, estandarizado a razón del flujo económico de intercambios que así lo exige. Pues, para vincular jurídicamente a la producción masiva de bienes y servicios con el consumo de los mismos, se consolida una "nueva forma de contratación también masiva", más rápida, e inspirada en la brevedad para regular y efectivizar relaciones de intercambio económico.

\footnotetext{
${ }^{21}$ Citado por: De La Puente y Lavalle, Manuel. Op. Cit., p. 689.

22 VAllespinos, Carlos Gustavo. Op. Cit., p. 180. Alfaro Pinillos por su parte señala como principales causas del surgimiento de la contratación masiva las siguientes: 1) acelerado desarrollo tecnológico y acentuado incremento poblacional, 2) necesidad de suministro masivo de bienes y servicios, 3) presencia de monopolios empresariales, 4) aún, no habiendo monopolios, se hace necesario la contratación en masa, 5) creación de nuevos, mejores y más rápidos modos de producción (producción en serie, masivos o a gran escala); y 6) estandarización en el modo masivo de producción de bienes y servicios (exclusión de la etapa de negociación o tratativas, ALFARO PINILLOS, Roberto y VelARDE SUSSONI, Jorge. Compendio Práctico de Contratos Civiles, Comerciales, Bancarios e Informáticos. Lima: Editorial San Marcos, 2003, p. 83.
} 


\section{LA CONTRATACIÓN MASIVA}

\subsection{Definición de contratación masiva}

El maestro De La Puente considera que la contratación masiva constituye un "sistema de contratación", en el cual el contenido del contrato ya no es el producto, el resultado del acuerdo conjunto de las partes, sino que éste es predispuesto total o parcialmente por una sola de ellas con antelación a su celebración. Y en este sentido, hoy en día esta forma de contratación se ha convertido en la regla, desplazando a la contratación negociada que a pasado a constituirse en un medio de contratación excepcional ${ }^{23}$. Pues las negociaciones y los tratos preliminares tendientes a lograr un acuerdo acorde a los intereses de las partes, han sido dejados de lado. El tráfico masivo ha coaccionado hacia el uso generalizado del contrato masivo o predispuesto.

Es fácil advertir que la contratación masiva se desarrolla bajo un esquema contractual previamente determinado por uno de los sujetos contratantes, con la consecuente disminución y en algunos casos hasta la eliminación de la etapa negocial. Lo importante, dada la celeridad exigida, es la preeminencia de la predisposición unilateral del contenido del contrato.

Los sujetos que intervienen en las relaciones contractuales masivas presentan algunas peculiaridades que los diferencian de los intervinientes en otro tipo de contratos. Las partes contractuales que concurren en el mercado por lo general comprenden a quienes producen o proveen de bienes y servicios, $\mathrm{y}$ a quienes los consumen, pero ambos sumidos dentro de relaciones de intercambio masivas. Se trata de contratos diseñados para realizar innumerables transacciones entre los individuos que conforman las masas. Esa es la cualidad, uno de los motivos de la existencia de la contratación masiva. Pues ante la existencia de productos masivos y un consumo masivo, corresponde un contrato también masivo que los vincule jurídicamente y distribuya en cada parte contractual individualizada, derechos y obligaciones.

Así pues, la masificación generalizada impuso las condiciones que debería reunir esta nueva forma de contratación, más rápida, menos onerosa y que haga en lo posible más eficientes las transacciones patrimoniales en el mercado. Pero estas "condiciones" impuestas por el tráfico económico se reflejaron en la disminución y hasta la supresión de una etapa que resultaba trascendental en la celebración de un contrato paritario: "la negociación". La

${ }^{23}$ Véase: De La Puente y Lavalle, Manuel. Op. Cit., p. 71. 
rapidez dispuso obviar esta etapa contractual, lo cual ha conllevado incluso a negarle cualquier "carácter de contrato" a la contratación masiva ${ }^{24}$.

En esta línea, Diez Picazo anota que el contrato ha dejado de ser la obra común, el fruto del esfuerzo conjunto de los contratantes, capaz de consolidarse en una regla de conducta para las partes, pues ha sucedido que una de ellas tenga que limitarse a aceptar -o en su caso rechazar- el único contrato posible ${ }^{25}$. De igual forma, Soto Coaguila destaca que "el eje central de esta forma de contratar es que las partes ya no negocian el contenido del contrato, por lo tanto, la etapa previa del contrato -negociación o tratativas- no existe en sentido lato, ya que los contratantes no se reúnen y empiezan a discutir el contenido del contrato que pretenden concertar"26. Existe una evidente carencia de negociación, pues así lo exige la rapidez con que suelen ocurrir las transacciones económicas en el mercado.

La contratación masiva es entonces, un mecanismo contractual de intercambio masivo que hace posible la concatenación de los dos factores concurrentes del mercado, la producción masiva de bienes y servicios, y el consumo masivo, dotándoles de un vínculo jurídico obligacional. Constituye una forma de contratación que atiende a las exigencias del tráfico económico, manifestándose para ello a través de formularios prerredactados que permiten la contratación en serie de bienes y servicios, cuyos contenidos han sido fijados con anticipación a su celebración por una de las partes. Por su misma condición, limita y en ciertos casos no admite la negociación del contenido del contrato, pues lo que prima es la predisposición del esquema contractual.

\subsection{Características de la contratación masiva}

\subsubsection{Falta o limitación de la negociación}

De acuerdo a lo expuesto, es fácil identificar que una de las principales características de la contratación masiva es "la limitación o falta de negociación" en la formulación del contrato. Así lo hace notar Jimenez Vargas al señalar que "las partes no negocian el contenido de estos contratos; no existen tratativas, los

\footnotetext{
${ }^{24}$ De este criterio es por ejemplo Bullard, quien denomina a esta forma de intercambio como "transacciones estándar", puesto que considera que no existe contrato alguno, al haberse negado o suprimido la libertad de negociación de una de las partes del contrato. (Véase: Bullard GONZALES; Alfredo. "Contratación en masa. ¿Contratación?». En: Estudios de Análisis Económico del Derecho. Lima: Editorial Ara, 1996, p. 49-70).

25 Diez PiCAzO, Luis. «Fundamentos de Derecho Civil Patrimonial». Op. Cit., p. 131.

${ }^{26}$ Sото CoAguila, Carlos Alberto. «La contratación masiva y la crisis de la contratación clásica», Op. Cit., p. 118.
} 
contratantes no se sientan en una mesa a discutir las particularidades del contrato que pretenden celebrar"27. Lo que prima en los contratos masivos es la presencia de un "contenido" previamente elaborado de manera unilateral por una de las partes, generalmente aquella que de alguna manera se encuentra en una posición privilegiada que le otorga la facilidad de confeccionar el contenido negocial.

Esto conlleva, a que se genere un estado de compulsión en una de las partes para aceptar la oferta sin tener siquiera la posibilidad de negociar, de discutir o de proponer modificaciones al contenido contractual. Según Gorla esta situación representa una "restricción" que se emplaza a la libertad contractual o de autorregulación negocial cuando una de las partes, por no ser igual y, por ende, libre, carece del poder de participar en la redacción del contrato que viene, finalmente, predispuesto por quien ocupa una posición contractual predominante ${ }^{28}$.

Así pues, la anulación parcial o total de la capacidad para negociar el contrato en una de las partes, viene impuesta por la propia naturaleza de la contratación masiva. Las exigencias económicas y sociales que emplazan a los sistemas de contratación, reflejan la necesidad de contar con un medio expeditivo y ágil para concretar acuerdos masivos, con la consecuente alteración de la etapa negocial durante el curso del acuerdo ${ }^{29}$.

Esta característica trae como consecuencia inmediata lo que se conoce como la "predisposición contractual", pues solo una de las partes contractuales elabora previamente todo o la mayor parte el contenido del contrato, de manera que el otro contratante se encuentra ante la alternativa de aceptar en su integridad todos y cada uno de los términos estipulados unilateralmente, o en el mejor de los casos, tendrá la posibilidad de poder negociar pero solo determinados aspectos del contrato predispuesto.

La predisposición contractual del contrato masivo se materializa mediante esquemas o formularios prerredactados que permiten la celebración de contratos en serie, a gran escala. En la contratación masiva expone Ghersi, "el contrato está diagramado por el predisponente donde solo se ingresan a posteriori

\footnotetext{
27 JimeneZ VARGAS-MAChUCA, Roxana. Op. Cit., p. 522.

${ }_{28}$ Citado por: STiglitz, Rubén S. y STiglitz, Gabriel A. Contratos por Adhesión, Cláusulas Abusivas y Protección al Consumidor. Bs. As.: Editorial Depalma, 1985, p. 28.

29 Ampliando este aspecto Friedmann señala que la "uniformidad" es un aspecto inevitable de la mecanización de la vida moderna y en este sentido, la redacción de miles de condiciones contractuales individuales para transacciones esencialmente análogas, sería tan antieconómica como el uso de maquinaria anticuada. (Citado por: Rezzónico, Carlos. Op. Cit., p. 10).
} 
los datos personales del adquiriente o usuario" ${ }^{\prime 30}$. En este tipo de contratación se emplea un "único modelo", uniforme, que se usa sin variantes para todos los contratos que se celebren.

Esto ha permitido como explican los Stiglitz, de que frente a la producción masiva de bienes y servicios y un consumo igual de correlativo a las cantidades producidas, exista "homogeneidad de los esquemas contractuales".

\subsubsection{Despersonalización de las relaciones contractuales}

Otra característica que encontramos en la contratación masiva es la "despersonalización de las relaciones contractuales", es decir el anonimato que existe entre las partes que intervienen en la celebración de un contrato con características masivas. Para Soto Coaguila, lo más característico de este tipo de contratación es que su celebración se realiza en forma inconsciente, puesto que al consumidor o usuario simplemente le interesa adquirir el bien o utilizar el servicio a un menor precio y en forma rápida; y al proveedor, comercializar el mayor número de bienes o servicios ${ }^{31}$.

De modo, constituye una nota característica de estos contratos, que las relaciones contractuales se establezcan con prescindencia de la identificación e interés en conocer recíprocamente al otro contratante, pues así lo exige la agilidad con que suceden las transacciones económicas masivas.

\subsubsection{Elaboración en forma masiva o estandarizada}

Finalmente, también es una característica de la contratación masiva, su "elaboración en forma masiva o estandarizada". Los contratos masivos se generan en serie y por lo general tienen el mismo contenido, pretendiendo de este modo satisfacer las exigencias de rapidez y eficiencia que requieren las múltiples transacciones que tienen lugar dentro de la sociedad de masas, dentro de las necesidades que también son masivas requieren lógicamente de la presencia

\footnotetext{
${ }^{30}$ Citado por: BORDA, Alejandro. «La contratación en masa. Una actualización a la luz de la ley de defensa del consumidor argentina», Op. Cit., p. 269.

31 Sото CoAguila, Carlos Alberto. «La contratación contemporánea, el respeto a la autonomía privada y la protección a los contratantes débiles» En: Revista jurídica del Perú. Año LI, No 23, p. 68. El mismo autor ha comentado el hecho señalando lo siguiente: no hay duda de que nos encontramos inmersos en una sociedad de consumo, donde las personas contratan todo el tiempo sin saberlo, sin tener la mínima conciencia de que lo está haciendo, convirtiendo de este modo al contrato en un instrumento jurídico de mero intercambio de bienes y servicios entre sujetos despersonalizados y donde las condiciones vienen impuestas por el productor o proveedor". (Sото COAGUILA, Carlos Alberto. "La transformación del contrato: del contrato negociado al contrato predispuesto», Op. Cit., pp. 672-675).
} 
de este tipo de contratación como el mecanismo más adecuado para agilizar los intercambios. Si en el mercado se producen bienes y servicios en grandes cantidades, y a la vez existe un bloque igual de numeroso de consumidores, el contrato que vincule jurídicamente a estos dos factores, consecuentemente, también tiene que ser elaborado por miles.

\subsection{Funciones de la contratación masiva}

Con la presencia de la contratación masiva, se complementa la función que hasta ese entonces tenía el contrato tradicional. Conforme afirma Soto Coaguila ${ }^{32}$, la contratación masiva cumple una función económica, una función social, y una función netamente jurídica.

En cuanto a la función económica, el maestro Messineo señala que el contrato tiene una función y un contenido constante, "el de ser el centro de la vida de los negocios". Y en este sentido nos dice que realiza las más variadas finalidades de la vida económica ${ }^{33}$. Este papel que cumple la contratación masiva le permite agilizar el intercambio patrimonial de bienes y servicios en un medio con las características de rapidez y exigencia de requerimientos masivos.

La contratación masiva cumple también una función social al constituirse en el medio que permite la satisfacción de necesidades e intereses. De manera inmediata ayuda a concretar las aspiraciones de las partes contractuales, y de manera mediata, contribuye a lograr el bienestar general de la sociedad ${ }^{34}$. Pues, unos podrán vender o colocar sus productos en el mercado y otros podrán adquirirlos, al hacer esta operación económica de intercambio a través del instrumento de la contratación masiva, ambas partes logran satisfacer sus necesidades.

Finalmente, también cumple una función jurídica, connatural a su esencia contractual, pues como mecanismo jurídico de vinculación dota de eficacia jurídica a las relaciones masivas de intercambio de bienes y servicios.

\footnotetext{
32 Sото CoAguila, Carlos Alberto. «La contratación masiva y la crisis de la contratación clásica». Op. Cit., pp. 154-155.

${ }^{33}$ Messineo, Francesco. Doctrina del Contrato General. Tomo I. Bs. As.: Ediciones Jurídicas Europa-América, 1986, p. 34.

34 Messineo describe al respecto que dichos intereses, por el trámite del contrato hallan su satisfacción, generándose una utilidad de la que participan cada uno de los contratantes e indirectamente se beneficia también la sociedad. (Ídem, p. 34). También es conocida la teoría de "la mano invisible", consistente en que cuando el hombre actúa libremente en un mercado también libre, al satisfacer sus intereses prácticamente de modo natural, contribuye con la satisfacción de los intereses de los demás. (Véase: GUTIERREZ CAMACHO, Walter. «Economía de mercado y constitución». En: Contrato y Mercado. Op. Cit., p. 130).
} 


\section{EL ANÁLISIS ECONÓMICO DEL DERECHO CONTRACTUAL}

\subsection{El derecho y la economía}

No cabe duda que entre Derecho y Economía, existen puntos o áreas de conexión en las cuales ambas ramas confluyen y se relacionan mutuamente. Así, El hombre como ente biológico y social, se ve necesariamente inmerso dentro de toda una gama de necesidades que deberá satisfacer, pues como sostienen GRACIARENA y SAUTU, "toda sociedad es una manera organizada de vivir, pero también es una manera organizada de satisfacer las necesidades de todo tipo de sus miembros" ${ }^{\prime \prime}$.

Frente a estas necesidades el hombre, "para obtener su sustento, para alimentarse, para buscary seleccionar los bienes que satisfagan sus necesidades, ha tenido que desarrollar su ingenio. Esta actitud individual es la actividad económica, el homo economicus"36, compuesta por aquella inclinación natural destinada a la búsqueda de los elementos necesarios para satisfacer una serie de necesidades del hombre. Ello implica consecuentemente, la búsqueda de los medios necesarios para satisfacer tales necesidades, originándose un proceso que ha sido regulado por la economía y al cual se le ha denominado "proceso económico", el mismo que consiste en la búsqueda de los bienes y recursos que se requieren para satisfacer las múltiples necesidades del hombre.

No obstante, existe aquí un gran problema a resolver. Las necesidades que se buscan satisfacer son ilimitadas y por el contrario, los recursos requeridos para satisfacerlas son escasos y muy limitados. Surge así el clásico dilema que ha conllevado a considerar actualmente a la economía como una ciencia que estudia las decisiones racionales en un mundo -como el nuestro- en el que los recursos son escasos frente a las necesidades humanas que tiene que satisfacer ${ }^{37}$.

De no existir el Derecho, este problema económico (necesidades ilimitadas y escasez de recursos), que es uno de los más importantes que tiene que resolver la Economía, ocasionaría desorden, caos, una pugna constante entre los hombres y las naciones, quienes unos a otros tratarían de arrebatarse a

\footnotetext{
35 GRaCiarena, Jorge y SAUtu, Ruth. «Conceptos básicos de economía». En: Antología. De la Sociedad Tradicional a la Sociedad de las Masas. Bs. As.: Editorial J.M. Álvarez, 1964, p. 224.

36 SIERRAlta Ríos, Aníbal. Introducción a la Juseconomía. Segunda Edición. Lima: Fondo Editorial PUCP, 1996, p. 8.

37 Posner, Richard A. El Análisis Económico del Derecho. México: Editorial Fondo de Cultura Económica, 1998, p. 3 .
} 
cualquier costa los mismos bienes escasos que a su vez otros desearían para satisfacer sus múltiples necesidades.

En este estado de cosas, de eventuales conflictos, del requerimiento de un sistema adecuado para la asignación de los recursos, es necesario contar con medios adecuados de regulación. Pues, "la restitución de esa armonía, que a la vez permita una utilización acorde de los bienes, ocasiona la necesidad de ordenar el actuar humano. Una nueva actividad: el homo iuridicus" ${ }^{38}$.

De esta manera, el Derecho interviene para regular las conductas de los individuos y de las sociedades, con el objeto de evitar la existencia de eventuales conflictos, resolviendo los ya producidos y permitiendo la satisfacción de las necesidades de la manera más armoniosa y eficiente posible. Así también lo entiende Bullard, "las leyes buscan que las personas ajusten su comportamiento a cierto conjunto de reglas, y el objetivo es que esos patrones nos conduzcan a una auténtica convivencia social, es decir a un mundo ideal en el que no haya conflictos" ${ }^{39}$.

Según lo anotado, compartimos la idea de que las primeras manifestaciones en que conjugan el Derecho y la Economía son en el disfrute posesorio de los bienes, el derecho los protege permitiendo su goce pacífico ${ }^{40}$.

Para el maestro De Trazegnies, "la influencia de lo económico sobre el Derecho puede darse como una transposición sobre el Derecho. Puede darse como una transposición inmediata del interés económico en términos jurídicos, es decir, de manera que esta transparencia de la norma permita determinar directamente el interés económico que la inspira"41.

\subsection{El análisis económico del derecho (AED)}

Sierralta expone que el origen del análisis económico del derecho (en adelante AED) es el sistema anglosajón y se sustenta en "la regla de los precedentes, del instrumento teórico y los principios consuetudinarios que obligan

\footnotetext{
38 Sierralta Ríos, Aníbal. Op. Cit., p. 8.

39 Bullard GONZÁLES, Alfredo. «¿Qué es el análisis económico del derecho?». En: Scribas, Revista de Derecho. Número 13, 2002, p. 173.

40 Sierralta Rios. Aníbal. Op. Cit., p. 6. En el mismo sentido, el autor citado precisa que la intervención del Derecho como regulador en la obtención de los bienes para la satisfacción de las necesidades, que es el objetivo fundamental de la Economía y el origen común que tienen ambas ciencias, determina su evidente relación, pero no significa la sujeción de la primera a la segunda, ni que el Derecho sea fundamentalmente una consecuencia de la producción, pues aun cuando se interprete en muy amplio sentido el concepto de Economía, no puede constituir su contexto exclusivo. (Ídem., p. 19).

${ }^{41}$ Citado por Malpartida Castillo, Víctor. Introducción al Derecho Económico. Análisis Económico del Derecho y Derecho al Desarrollo. Lima: Editorial San Marcos, Lima, 1996, p. 46.
} 
jurídicamente a los individuos porque las han observado o mantenido en un horizonte dado de tiempo y se convierten en derecho positivo (positive law), cuando son aplicadas por los tribunales" ${ }^{\prime 2}$.

En AED en palabras de Pastor Santos "consiste en la aplicación del análisis económico al estudio del funcionamiento del sistema jurídico, de los problemas más importantes del Derecho. Este análisis es un método o enfoque que se aplica a un objeto distinto de aquel para el que fue concebido (el sistema económico), sustituyéndolo por el sistema jurídico" ${ }^{43}$.

El AED ha contribuido con criterios, mecanismos y procedimientos mediante los cuales trata de explicar los efectos y la eficiencia, desde un enfoque económico, de las leyes y de las instituciones jurídicas. Mackay destaca la idea anotando que "es esencial considerar los efectos (económicos) que tales instituciones tienen sobre la sociedad y que resultados generan para los ciudadanos" $^{\prime 4}$.

Bullard Gonzáles, uno de los más grandes exponentes y difusores del AED en nuestro país, manifiesta que el AED "se trata de la aplicación del método del razonamiento económico al Derecho. Debe destacarse, sin embargo, que no se pretende reemplazar el razonamiento jurídico; sólo se pretende complementarlo a través del uso de una perspectiva diferente" ${ }^{\prime 4}$. Esto nos lleva a considerar por un lado, que el Derecho no es una isla alejada de las demás áreas del conocimiento, sino que es un aspecto más que conjuntamente con otros complementan el saber humano y, por otro lado, mediante la aplicación de los métodos económicos, se busca salir del análisis tradicional para obtener nuevos enfoques que proporcionan una explicación fuera de lo usual y sobre todo útil para la conducción y el fortalecimiento del sistema jurídico en su conjunto.

En tal sentido, el AED puede ayudarnos a observar e incluso descubrir perspectivas interesantes en las distintas manifestaciones del Derecho, permitiéndonos "entender los fenómenos económicos frente al Derecho, a la administración de la justicia, así como a los criterios para estructurar la ley"46.

\footnotetext{
42 Íbid., pp. 36-37. El análisis económico del derecho también conocido como "AED”, es denominado en Estados Unidos y en algunos países bajo la influencia del sistema jurídico anglosajón como "Law E Economics" o "Economics of Law".

43 Citado por Malpartida Castillo, Víctor. Op. Cit., p. 52.

44 Citado por Alfaro Pinillos, Roberto y Velarde Sussoni, Jorge. Op. Cit., p. 106.

45 Bullard GONZÁLES, Alfredo. «iAl fondo hay sitio! ¿Puede el teorema de Coase explicarnos el problema del transporte público?» En: Estudios de Análisis Económico del Derecho. Lima: Editorial ARA, 1996, p. 140.

46 Sierralta Ríos, Aníbal. Op. Cit., p. 110.
} 
En todas las definiciones que se han ensayado acerca del análisis económico del derecho y que no difieren sustancialmente unas de otras, es posible destacar dos aspectos en esta disciplina, su rol normativo y su rol positivo. El primero se presenta como una función reguladora y preventiva de cambios futuros para mejorar el sistema jurídico, y el segundo, como alcanza Posner radica "en el intento de explicar las reglas y los resultados legales tal como son" ${ }^{47}$.

Con la aparición del AED, se admitieron diversas aplicaciones en las esferas jurídicas como el Derecho Penal, el Derecho Civil, el Derecho Constitucional, el Derecho Comercial, el Derecho Procedimental, entre otras ramas, a fin de analizar con métodos proporcionados por el AED, el funcionamiento de las diversas normas e instituciones jurídicas.

Estas aplicaciones giran en torno al elemento central que sustenta la teoría del AED: "la eficiencia". Así, el sistema jurídico es analizado para determinar la eficiencia de sus normas e instituciones jurídicas, partiendo de la estrecha relación entre el Derecho y la Economía. Pues debe tenerse en cuenta que “El Derecho y la Economía no están para explicarse así mismas, sino para permitirnos entender, de una mejor manera, la propia realidad con la que están comprometidas" ${ }^{48}$.

Dentro del AED, particularmente no interesa el análisis económico de Ronald Coase basado en los "costos de transacción", que permitió un mejor entendimiento de cómo funciona el sistema jurídico. Pues como destaca Bullard, el concepto de costos de transacción nos explica por qué no todo se puede solucionar a través del mercado ${ }^{49}$.

A partir de allí se empieza a delinear que la función del sistema jurídico consiste "en primer lugar, en intentar reducir lo más posible los costos de

\footnotetext{
47 POSNER, Richard A. Op. Cit., p. 28.

48 Bullard GONZÁLES, Alfredo. «Ronald Coase y el sistema jurídico. Sobre el Nobel en Economía». En: Estudios de Análisis Económico del Derecho. Lima: Editorial ARA, 1996, p. 135.

49 Bullard GonZÁles, Alfredo. «Ronald Coase y el sistema jurídico. Sobre el Nóbel en economía». Op. Cit., p. 135. Ronald Harry Coase, es considerado como el fundador del análisis económico del derecho o Law of Economics. En 1960 publica su obra cumbre "El Problema del Costo Social" o "The Problem of Social Cost", a la que posteriormente se la conoce como el "Teorema de Coase". Ronald COASE, considerado como uno de los mejores tratadistas del análisis económico del derecho, fue galardonado con el Premio Nobel a la economía en el año 1991. Este destacado profesor formula un postulado, el "Teorema de Coase", basándose en un concepto fundamental conocido como los "costos de transacción" cuya definición radica básicamente en la idea que "celebrar un contrato cuesta. La genialidad de Coase radica en haber descubierto y explicado el significado de los costos de transacción y de los derechos de propiedad económicos para la estructura institucional y el funcionamiento de la economía, haciendo con ello una aporte valioso para el entendimiento del sistema jurídico.
} 
transacción -origen de toda externalidad- y en segundo lugar, cuando ello sea virtualmente imposible, cuando no puedan ser reducidos los costos de transacción, la función de la intervención pública consiste en decidir la cuestión (asignar los costos y los beneficios, los derechos) tal y como lo habría hecho el mercado, como un mercado simulado, asignando los recursos a aquella parte en que éstos resultan más valiosos" ${ }^{\prime \prime}$.

El empleo conceptual de los costos de transacción en el ámbito contractual permite evidenciar que todo contrato implica un costo, y que depende del nivel que implique dicho costo, la adopción de una "decisión eficiente". Desde este punto de vista para Sierralta el Teorema de Coase se puede resumir en el principio de que "el intercambio solamente puede ser hecho cuando beneficia a ambas partes" ${ }^{\prime 51}$.

\subsection{El análisis económico del contrato}

En el campo del Derecho de los Contratos, el empleo del AED ha proporcionado nuevas luces que han permitido el mejor funcionamiento de las instituciones contractuales. El análisis económico ha facilitado la comprensión de la enorme importancia del contrato como mecanismo de vinculación jurídica y facilitador del intercambio patrimonial en el tráfico económico.

Bullard nos explica claramente: "para que el mercado funcione requiere de una asignación inicial de los recursos de manera que el titular de cada uno esté en capacidad de excluir a los demás de su uso y disfrute. Esto se logra, primordialmente, a través del sistema de propiedad. Pero se requiere adicionalmente que dichos recursos cuenten con cierta movilidad que le permita dirigirse a sus usos más valiosos. Esta función está asignada al sistema contractual, que presta las garantías para una fluida circulación de los recursos y para impedir la aparición de fenómenos anómalos que distorsionen la función que se le ha asignado" 52 .

Carbone y D'angelo precisan que la regulación contractual es un elemento imprescindible dentro del plano económico, pero no obstante indican, la regulación jurídica de la relación no es el ropaje formal con que vive el negocio, sino que constituye el esqueleto de la estructura misma de la

\footnotetext{
${ }^{50}$ FALla JARA, Alejandro. «Responsabilidad civil y eficiencia económica: Matrimonio por conveniencia». En: Themis, Revista de Derecho. Segunda época, 1992, No 24, p. 84.

51 Sierralta Ríos, Aníbal. Op. Cit., p. 118.

52 Bullard GonZÁles, Alfredo. «Contrato e intercambio económico». En: Derecho y Economía. El Análisis Económico de las Instituciones Legales. Primera edición. Lima: Palestra Editores, 2003, p. 192.
} 
operación económica ${ }^{53}$. El contrato, es en esencia, el mecanismo jurídico en que concluye el intercambio patrimonial. Es la estructura, el esquema que adopta toda transacción económica y que se hace evidente a través del contrato. En este sentido, es indudable el carácter económico, connatural y constitutivo que prospera en el contrato, y que básicamente se hace evidente a través de una función económica, que deriva del propio ordenamiento legal. Pues así se desprende de nuestro ordenamiento civil, que en su artículo $1351^{\circ}$ lo considera como un acuerdo contenido patrimonial. La propia concepción legal del contrato, le otorga el estatus de medio de regulación patrimonial o económica por excelencia, de los intereses de los contratantes.

Así entonces, la confluencia entre el Derecho y la Economía en la tarea de la asignación de recursos escasos se manifiesta concretamente en el contrato, que representa el instrumento jurídico que aporta el Derecho para canalizar el tráfico económico de bienes y servicios. Malpartida precisa "el derecho contractual cumple la función de permitir que los sujetos contratantes intercambien recursos, y a través de este intercambio se dé una asignación de recursos escasos a su uso más valioso. Esto permitirá alcanzar el máximo beneficio social" 54 . Hay que tener en cuenta que es precisamente en el intercambio patrimonial de bienes y servicios que se canaliza a través del contrato, donde los costos de transacción que deben soportar las partes a fin de realizar sus transacciones, nos pueden ayudar a explicar cuando un contrato puede resultar viable y eficiente para las partes y cuando no.

A partir de los postulados del Teorema Coase, el contrato representa la evidencia más clara de que los costos de transacción han sido lo suficientemente bajos que han permitido a las partes llegar a un acuerdo, con prescindencia de alguna regulación jurídica ${ }^{55}$. Pues hay que tener en cuenta que los costos de transacción son los costos de celebrar un contrato, y que en ciertas circunstancias, si éstos resultan demasiado elevados, podrían evitar que el acuerdo se perfeccione, o llevar a que éste se perfeccione en términos ineficientes. Es decir, la presencia del contrato manifiesta que el producto de una transacción ha tenido un resultado eficiente para los intereses de los contratantes ${ }^{56}$.

53 Citado por D’Angelo, Angélica. «Contrato y operación económica». En: Estudios sobre el Contrato en General. Segunda edición. Lima: Ara Editores, 2004, p. 650.

54 Malpartida Castillo, Víctor. Op. Cit., p. 61.

55 Alfredo Bullard indica al respecto que si los costos de transacción son lo suficientemente bajos como para hacer viable una solución contractual, la existencia de una regla legal es inocua para alcanzar el resultado final. (BULLARD GONZÁLES, Alfredo. «iAl fondo hay sitio!: puede el teorema de Coase explicarnos el problema del trasporte público», Op. Cit., p. 147).

56 İdem, p. 145. Sin embargo precisa Bullard que el Teorema de Coase nos enseña que la diferencia radica no en si hay o no contrato, sino en la capacidad que tiene el sistema contractual, dados los costos de transacción 
La viabilidad del contrato y su posterior concreción, dependerá de cuan significativos sean los costos de transacción originados según destaca Malpartida, en la identificación, reunión, posterior negociación y efectivo cumplimiento de lo acordado, costos que las partes tienen que soportar para poder llevar a cabo la celebración del contrato. Pues como precisa el mismo Coase, para llevar a cabo transacciones de mercado, es necesario descubrir con quien deseamos transar, comunicar nuestro deseo de intercambiar y en qué términos, conducir negociaciones que conlleven a un convenio, redactar el contrato, llevar a cabo las diligencias necesarias para asegurarnos que los términos del contrato tengan que cumplirse y demás ${ }^{57}$.

Los costos de transacción no son otra cosa que los costos de información, identificación, dinero, tiempo y esfuerzo que tienen que tolerar los particulares si su deseo es llevar a cabo alguna relación contractual. En palabras de Bullard, "celebrar un contrato cuesta". De aquí la enorme importancia que cumplen los costos de transacción durante toda la secuencia del contrato, durante la fase preparatoria, y desde que existe hasta que se extingue. En esta línea, los costos de transacción constituyen una suerte de factores condicionantes de la existencia del contrato, pues cuando los costos de celebración sean sumamente onerosos, costosos para las partes, puede frustrarse cualquier iniciativa de concertar algún contrato.

Esto repercute directamente en el grado de eficiencia del contrato. Según ilustra Cantuarias estos costos pueden conllevar a que aún cuando una transacción pudiera ser eficiente, los costos presentes podrían evitarla o en todo caso permitir que se genere pero en condiciones más onerosas. Así también lo destaca Soto Coaguila cuando señala que es un rasgo característico de los costos de transacción que cuando sean demasiado elevados, las partes optarán por no contratar, o si contratan, deberán asumir el riesgo de que dicho contrato resulte ineficiente ${ }^{58}$.

La eventualidad de que se generen situaciones de ineficiencia explica Cantuarias, "demanda a que el Derecho deba ingresar a regular el campo contractual, creando los mecanismos que reduzcan dentro de lo posible los "costos de transacción", a fin de viabilizar la celebración de transacciones

existentes, para llegar a una eficiente asignación de recursos”. (BULLARD GONZÁLES, Alfredo. «iAl fondo hay sitio!: puede el teorema de Coase explicarnos el problema del trasporte público», Op. Cit., p. 147).

57 Citado por MalPartida Castillo, Víctor. Op. Cit., p. 62.

58 Soto CoAguila, Calos Alberto. "La transformación del contrato: del contrato negociado al contrato predispuesto», Op. Cit., p. 698. 
privadas eficientes"59. Es así como el Derecho Contractual ha creado determinados mecanismos que hacen posible no solo la existencia del contrato, dotando a los particulares de la posibilidad de contratar, sino además que su celebración se realice con costos accesibles para las partes.

Bullard indica que son dos los mecanismos que el Derecho Contractual ha desarrollado para reducir los costos de transacción a efectos de permitir una contratación eficiente:

a. La existencia de normas supletorias de la voluntad de las partes, que reducen la necesidad de las partes de prever todas las contingencias posibles en el periodo de la negociación y,

\section{b. La existencia de cláusulas generales de contratación y de contratos por} adhesión, que reducen al mínimo los costos de transacción existentes en la etapa de negociación ${ }^{60}$.

La incidencia del AED, específicamente en el contrato, se evidencia mediante la implantación de dos medios para reducir los costos de transacción. Por un lado, mediante normas civiles contractuales de carácter dispositivo, que son supletorias de la voluntad de las partes y que constituyen el telón de fondo del contrato, donde se prevé todos aquellos aspectos que fueron obviados por las partes y que de ser regulados privativamente resultarían demasiado onerosos. El mismo Bullard anota que "no es necesario que las partes al negociar el contrato, se pongan de acuerdo sobre todas las posibles contingencias que pudieran surgir, pues en lo que no se haya acordado se aplican las normas del Código Civil que son supletorias al acuerdo de voluntades"61.

El otro mecanismo de reducción de costos de transacción que ha previsto el Derecho Contractual, son las cláusulas generales de contratación y los contratos por adhesión, que son modalidades de la contratación masiva que han sido regulados por nuestro Código Civil vigente. Estas modalidades contractuales tan comunes en el comercio, simplifican la etapa de negociación del contrato, limitándola al mínimo o anulándola por completo. Los gastos que comúnmente afrontaban las partes para negociar un contrato son eliminados o reducidos mediante estas formas de contratación masiva.

59 CANTUARIAS, Luis Felipe. «La función económica del Derecho; a propósito de los derechos reales de prenda e hipoteca». En: El Derecho Civil Peruano. Lima: Fondo Editorial de la Pontificia Universidad Católica del Perú, mayo de 1993, p. 59.

${ }^{60}$ Véase: Bullard GONZÁLES, Alfredo. «iAl fondo hay sitio!: puede el teorema de Coase explicarnos el problema del trasporte público». Op. Cit., p. 150.

${ }_{61}$ BULlaRd GONZÁLES, Alfredo. «iFirme primero, lea después! La contratación masiva y la defensa del consumidor». En: Estudios de Análisis Económico del Derecho. Op. Cit., p. 242. 
La presencia de estos contratos obedece a que nos encontramos en la segunda formulación del Teorema de Coase. Cuando los costos de transacción son tan significativos que hacen imposible arribar a un acuerdo, se requiere una decisión legal, en este, de unos contratos masivos que abrevien los costos de transacción.

En este supuesto del Teorema cousiano los costos de transacción tienen una participación esencial en el contrato, pues al ser los costos sumamente elevados, requieren de la provisión o reconocimiento de mecanismos jurídicos, en este caso por medio de las cláusulas generales de contratación y los contratos por adhesión, para reducir e internalizar los costos de la transacción, que bajo el contexto de los intercambios masivos en el mercado, no podrían ser asumidos por las partes.

De este modo, el Derecho de los Contratos a partir de los postulados del Teorema de Coase, nos ayuda a explicar que cuando el contrato resuelve las discrepancias de las partes a través de un acuerdo es que los costos de transacción son sumamente reducidos y pueden ser asumidos por la partes sin problema alguno. Así lo destacan también Alfaro y Velarde al sostener que "el derecho de los contratos se aplica en los casos en los que, típicamente, los costos de transacción son lo suficientemente bajos como para permitir a los individuos llegar a la solución más eficiente" ${ }^{\prime \prime 2}$. Pero cuando estos costos son prohibitivos, es necesaria la intervención de las normas del sistema contractual para que reduzcan prudentemente los costos de transacción, simulando el acuerdo, entendido como negociación o tratativas, al que las partes se hubieran sometido, pero que al resultar sumamente oneroso jamás hubieran podido concluir un contrato, o de haberse dado el contrato, este se vuelve ineficiente por los enormes gastos que para su celebración han tenido que soportar las partes.

Finalmente, Cooter ${ }^{63}$ señala que el Derecho de los Contratos visto desde el análisis económico del derecho, cumple los siguientes propósitos:

a. Primer propósito: Es el de permitir que los individuos conviertan los juegos de soluciones ineficientes en juegos de soluciones eficientes.

b. Segundo propósito: Es obtener el compromiso óptimo de cumplir.

c. Tercer propósito: Es asegurar una confianza óptima.

62 Citado por Pinillos Alfaro, Roberto y Velarde Sussoni, Jorge. Op. Cit., p. 136.

63 Ibid., pp. 128-129. 
d. Cuarto propósito: Es la minimización de los costos de transacción de la negociación contractual mediante la provisión de términos de omisión eficiente. (Ver: C.C. Peruano de 1984 art. 1356, aplicación supletoria de las normas contractuales).

e. Quinto propósito: Es corregir las fallas del mercado mediante la regulación de los términos de los contratos. (Ver: C.C. Peruano de 1984 art.1440 y s.s., "excesiva onerosidad de la prestación" o teoría de la imprevisión y art. 1346 "modificación del monto de la cláusula penal").

f. Sexto propósito: Es promover las relaciones permanentes, las que resuelven el problema de la cooperación con la menor utilización de los contratos.

A ello cabría agregar, la presencia de los contratos masivos, como son las cláusulas generales de contratación y los contratos por adhesión, que hacen más rápido y expeditivo el intercambio económico de bienes y servicios en el tráfico masivo, reduciendo los costos de negociación, al abstraer esta etapa del contrato de la esfera privada de los contratantes.

\section{LA FUNCIÓN ECONÓMICA DE LA CONTRATACIÓN MASIVA}

Los contratos por adhesión y las cláusulas generales de contratación son dos modalidades o expresiones de la denominada contratación masiva. La consolidación de estos contratos en nuestro Código Civil vigente como formas contractuales masivas, obedece a cuestiones eminentemente económicas y sociales, a la celeridad del tráfico de bienes y servicios, y a la necesidad de un medio de vinculación jurídica "masiva", con capacidad de responder sus exigencias.

Desde el Teorema de Coase las cláusulas generales de contratación y los contratos por adhesión, constituyen uno de los dos mecanismos reductores de costos de transacción que a puesto en funcionamiento el Derecho Contractual para canalizar de manera rápida y eficiente, la producción masiva de bienes y servicios hacia la satisfacción de innumerables necesidades también masivas. Ambos contratos masivos operan reduciendo los términos contractuales de la etapa de negociación, haciendo accesible para los contratantes la posibilidad de adquirir tales bienes y servicios cuya asignación, dentro del escenario actual del intercambio económico se ha vuelto de imperiosa necesidad.

La simplificación de la negociación en el contrato acarrea como consecuencia que la elaboración de esta etapa contractual sea realizada por una sola de 
las partes. En este sentido se señala: "la estandarización de los bienes y servicios que concurren al mercado lleva, indefectiblemente, a estandarizar las relaciones jurídicas vinculadas a dicha concurrencia. Las relaciones jurídicas se producen en serie. Ello exige eliminar los costos externos que ocasiona la negociación, lo que no es posible sin eliminar o limitar a ésta última. Así, la consecuencia lógica es la eliminación de la voluntad de una de las dos partes, de manera que la configuración de la relación jurídica sea una labor encargada a una de ellas" ${ }^{64}$. Con ello se alcanza reducir los costos de transacción sobre todo para una de las partes del contrato, aquella que carece de los medios económicos y de la posibilidad para afrontar la eventual negociación de un contrato de naturaleza masiva que en términos de eficiencia, dados los enormes costos que implica contratar en el mercado, resultaría inviable la negociación.

La única forma de reducir los costos para contratar es limitando o en ciertos casos eliminando la negociación del contrato. Bullard anota que así como las empresas han logrado reducir los costos en la producción estandarizando el proceso productivo, también han logrado reducir los costos de transacción estandarizando los términos contractuales de los bienes que ellas mismas producen ${ }^{65}$.

Morello y Stiglitz, señalan que los mecanismos de formación del contrato han experimentado una alteración debido al encarecimiento de la atmósfera consensual ${ }^{66}$. Es decir, si contratar cuesta, es lógico que desde la perspectiva del análisis económico la tendencia sea la de reducir al mínimo los costos de transacción que implica celebrar un contrato en el mercado, a fin de permitir a los eventuales contratantes celebrar un acuerdo eficiente, aunque para ello se requiera limitar o en ciertos casos anular por completo la negociación contractual.

Para Vega Mere, "los productos requieren ser colocados prontamente en el mercado, sin trabas, sin ataduras, sin necesidad de negociar de modo

\footnotetext{
${ }^{64}$ BULLARD GONZÁLES, Alfredo. «La contratación en masa. ¿contratación?». En: Estudios de Análisis Económico del Derecho. Op. Cit., p. 56.

65 Véase: Bullard GONZÁLES, Alfredo. «Firme primero, lea después! La contratación masiva y la defensa del consumidor», Op. Cit., p. 241.

${ }^{66}$ Citados por: STIglitz, Rubén S. y STiglitz, Gabriel A. Op. Cit., p. 27. Soto Coaguila expone sobre el asunto: "En este sistema de contratación la libertad contractual o de configuración interna del contrato se encuentra reducida o anulada en aras de la fluidez del intercambio de bienes y servicios a un menor costo, pues en la contratación masiva se reducen los costos que genera la contratación individual de cada contrato". (SOTO CoAguila, Carlos Alberto. «La autonomía privada y la buena fe: fundamentos de la fuerza obligatoria del contrato». En: Cuadernos de Doctrina del Colegio Público de Abogados de la Capital Federal. Buenos Aires, Septiembre, 2002, p. 63).
} 
diverso bienes similares: el contrato de los Códigos debe ser reemplazado por el contrato prerredactado por las empresas, por sus provisiones, por sus cláusulas de aplicación general a todos sus acuerdos, aun a costa de la preciada libertad contractual de una de las partes (la anónima, la masificada, la que sólo vale en estadísticas, en números)" ${ }^{\prime 67}$.

Sin embargo, esa es la función reductora de costos de transacción que cumplen los contratos masivos como las cláusulas generales de contratación y los contratos por adhesión, costos que resultarían demasiado prohibitivos para ser asumidos por los negociantes. Es así que en aras de evitar estos costos y a fin de dotar de mayor fluidez al tráfico contractual, se recurre a este tipo de contratos como mecanismos para asignar de manera rápida y eficiente la enorme producción de bienes y servicios.

En tal sentido, los contratos masivos son una exigencia real de carácter económico y social. De índole económica, por cuanto evitan que los contratantes soporten costos excesivos cuando deseen celebrar un simple contrato, facilitando el intercambio económico. Y de carácter social, por cuanto constituyen dos mecanismos que facilitan el intercambio de bienes y servicios producidos en forma masiva, contribuyendo a la satisfacción de necesidades masivas y en última instancia, a la búsqueda de un bienestar general ${ }^{68}$.

Para acercarnos hacia una mejor comprensión de la verdadera función que viene desempeñando la contratación masiva, como los contratos por adhesión y las cláusulas generales de contratación, es necesario describirlos desde el campo de cuatro principios que gobiernan el tráfico económico masivo: el principio de eficiencia, el principio de la rapidez contractual, el principio de economía contractual y el principio de simplificación contractual.

\subsection{El principio de eficiencia contractual}

Polinsky, definiendo la eficiencia desde la perspectiva del AED señala que eficiencia "es la relación entre los beneficios totales de una situación y los costos totales de la misma"69. Aplicando el término al Derecho, Sierralta a manera de

\footnotetext{
67 Vega Mere, Yuri. Op. Cit., p. 32. (Ibid., p. 32).

${ }^{68}$ La finalidad de la contratación masiva radica en la fluidez del intercambio masivo de bienes y servicios, reduciendo al máximo los costos de negociación de los contratos que se celebren o concerten a fin de lograr un mayor tráfico patrimonial en forma eficiente. Todo esto permitirá, a su vez, que un número cada vez mayor de personas puedan acceder al consumo o a la utilización de los bienes y servicios. (SOTO COAGUILA, Carlos Alberto. «La transformación del contrato: del contrato negociado al contrato predispuesto», Op. Cit., p. 410).

69 POLINSKY, A. Mitchell. Introducción al Análisis Económico del Derecho. Barceona: Editorial Ariel, 1985, p. 19.
} 
ejemplo señala que una empresa puede producir un bien de alta calidad, pero si sus costos de producción son demasiado altos, nadie estaría dispuesto a comprarlo puesto que su adquisición implicaría pagar un precio muy elevado. Concluye sosteniendo que esa empresa en ese supuesto es ineficiente. De igual forma, si una norma es técnicamente perfecta, en su origen, su formación, con exposición clara y conocida, pero sin embargo nadie o pocos están dispuestos a cumplirla, ni los jueces a aplicarla, entonces se puede decir que esa es una regla ineficiente ${ }^{70}$. Eficiencia en términos sencillos y concretos, es un beneficio esperado o alcanzado a base del empleo de costos más o menos equilibrados y capaces de ser soportados por las partes en relación directa al beneficio buscado.

En el derecho contractual existirá eficiencia si los costos que se requieren para celebrar un contrato -costos de transacción-, no sobrepasan el beneficio o la utilidad que buscan los contratantes dentro de los límites máximos de gastos en tiempo, dinero y esfuerzo que éstos hayan previsto para afrontar una situación contractual determinada.

El problema radica en que dado los costos de celebrar un contrato, es decir, de viabilizar un acuerdo a través del mercado, son demasiado caros para las partes, la única forma de disminuirlos es mediante los contratos masivos como las cláusulas generales de contratación y los contratos por adhesión, que actúan reduciendo del contrato los tratos preliminares, el área de negociación de las partes, permitiendo de este modo celebrar un contrato bajo los términos que exigen las relaciones de intercambio masivo. La presencia de estos contratos masivos torna más eficientes las relaciones contractuales, las hace menos onerosas para las partes y por tanto, realizables en términos de eficiencia. "Por lo tanto, para que el intercambio de bienes y la prestación de servicios en forma masiva sea eficiente para ambos contratantes empresarios y consumidores-, es necesario utilizar un contrato estandarizado o predispuesto" ${ }^{\prime 71}$.

Diez Picazo ha destacado la idea de que el contrato tradicional no concuerda con la contratación en masa de hoy en día. Pues un mínimo de criterio de racionalización y de organización empresarial determina la necesidad de contar

\footnotetext{
70 Sierralta Ríos, Aníbal. Op. Cit., p. 160.

${ }^{71}$ Soto CoAguila, Carlos Alberto. «La transformación del contrato: del contrato negociado al contrato predispuesto», Op. Cit., p. 376. Friedrich Kessler manifiesta al respecto: “De la misma manera como la reducción de los costos de producción y distribución se refleja en precios más reducidos, la sociedad en su conjunto se beneficia finalmente del uso de los contratos standards". (BULLARD GONZÁLES, Alfredo. «iFirme primero, lea después! La contratación masiva y la defensa del consumidor». Op. Cit., p. 241).
} 
con un contrato único, previamente elaborado y preestablecido por medio de impresos o formularios, lo cual reduce o evita los costos de negociación que la empresa tendría que afrontar para entablar relaciones contractuales con sus eventuales clientes ${ }^{72}$. Esto demuestra que la eficiencia en la contratación contemporánea mejora notablemente las relaciones contractuales para ambas partes, para el empresario y para el consumidor o usuario, al evitarles enormes costos de negociación de un contrato. Así lo destaca también el gran Messineo cuando diserta: "Dichos intereses, por el trámite del contrato, se combinan de manera que cada cual halla su satisfacción; de esto deriva, en el conjunto, un incremento de utilidad, de la que participan en varias medidas cada uno de los contratantes, mientras que indirectamente se beneficia también la sociedad"73.

Ello explica la función económica que cumple la contratación masiva, como mecanismo que tiende hacia la búsqueda de la ansiada eficiencia mediante la reducción de los costos en las transacciones contractuales. Así por ejemplo, si deseo adquirir un servicio de telefonía móvil, y en la eventualidad de que no existiesen los contratos masivos, deberé soportar una serie de gastos o costos de transacción, informarme sobre cual servicio tiene mayor cobertura, que empresas prestan el servicios, las marcas y modelos que existen, y elegir el que se encuentra dentro de mis posibilidades. Luego, tendría que reunirme con el propietario de la empresa telefónica elegida para negociar cada cláusula que irá en el contrato, prevenir cualquier tipo de riesgo y redactar el contrato. Así sucesivamente, tendría que incurrir en una "serie de gastos" (tiempo empleado, dinero, pérdida de oportunidades para el empresario y para mi de celebrar otros contratos etc.), costos que finalmente harían que los recursos empleados para celebrar el contrato superen grandemente mi beneficio buscado (adquirir un servicio de telefonía móvil), lo que equivale a decir que estaríamos frente a una situación ineficiente.

Dentro de la esfera del principio de eficiencia, siguiendo la opinión de Malpartida, el Derecho Contractual cumple la función de permitir que los sujetos intercambien recursos, y a través de este intercambio -por medio del acuerdo voluntario-, es decir del contrato, se dé la asignación de los recursos escasos a su uso más valioso, permitiendo el máximo beneficio social ${ }^{74}$.

\footnotetext{
${ }^{72}$ Diez PICAZO, Luis. «Fundamentos de Derecho Civil Patrimonial». Op. Cit., p. 131.

73 MessineO, Francesco. Op. Cit., p. 34.

74 Véase Malpartida CASTILlo, Víctor, Op. Cit., p. 61. Para Bullard la idea esencial consiste, en lograr decisiones eficientes mediante el aprovechamiento racional de los recursos existentes. (BULLARD GONZÁLES, Alfredo. «iAl fondo hay sitio! ¿Puede el teorema de Coase explicarnos el problema del transporte público?». Op. Cit., p. 142).
} 
A partir de este principio, las cláusulas generales de contratación y los contratos por adhesión, al permitir el intercambio de bienes y servicios no solo hacen eficiente directamente la relación contractual que afecta el ámbito privado de las partes reduciendo los costos de transacción que se verían obligados a afrontar; sino que repercute mediatamente en el bienestar de la sociedad, al complementar el puente de la asignación de recursos. Pues de darse un contrato oneroso por resultar excesivos los costos de transacción, la relación contractual podría resultar ineficiente para una o para ambas partes ${ }^{75}$.

\subsection{El principio de rapidez contractual}

Con el auge y la generalización de las relaciones de intercambio económico masivo, el contrato tradicional empezó a carecer de la rapidez necesaria para lograr la vinculación jurídica de innumerables transacciones comerciales, puesto que se requería de un mecanismo jurídico que otorgase esta nota de velocidad al comercio de bienes y servicios. Así, según Vallespinos "las exigencias del moderno tráfico en masa y la concentración de las necesidades de racionalización impuesta por la civilización industrial y urbana, con sus relaciones de velocidad y precisión, han traído, como sabemos, la estandarización de las relaciones contractuales" ${ }^{\prime \prime 6}$.

La contratación masiva representa la "solución jurídica" desde el Derecho Contractual a este acontecer económico, siendo una de sus características más saltantes la rapidez en la celebración masiva o en serie de contratos, otorgando agilidad y fluidez al tráfico patrimonial, pues como anota De La Puente, la velocidad es un factor determinante de este tráfico. Hedemann sostiene que un dato positivo de la contratación privada contemporánea es que al uniformizar los textos contractuales, esto es, mediante la concreción de contratos masivos, se "aumenta la seguridad y la rapidez" de la contratación, evitando caer en largas negociaciones ${ }^{77}$.

De este modo, la dinámica del Derecho Contractual debe estar acorde, guardar si es posible, una relación de correspondencia con el tráfico económico, con la rapidez que exigen las transacciones económicas que se presentan bajo el

\footnotetext{
75 No sería posible como anota Bullard a manera de ejemplo, imaginar al Presidente de la General Motors negociando, bajo la asesoría de un conjunto de abogados, todos los contratos de compraventa de automóviles que celebra la empresa. La burocratización administrativa, el tiempo y recursos perdidos, las demoras en la colocación de automóviles en el mercado, las dificultades para interpretar y en su caso cubrir los posibles incumplimientos de los particulares referidos a relaciones jurídicas de contenido diverso, hubieran hecho imposible el eficiente desarrollo que esta empresa ha alcanzado en el presente siglo (BULLARD GONZÁLES, Alfredo. «Contratación en masa: ¿Contratación?». Op. Cit., p., 56).

76 VAllespinOS, Carlos Gustavo. Op. Cit., p., 219.

77 Citado por Stiglitz, Rubén S. y STiglitz, Gabriel A. Op. Cit., pp. 27, 20.
} 
contexto del mercado ${ }^{78}$. Pues al ser el tráfico económico de carácter masivo, caracterizado principalmente por la producción estandarizada de bienes y servicios y el consumo masivo; entonces, la dinámica contractual a través de la contratación masiva debe otorgar eficacia práctica al Derecho Contractual a fin de evitar una suerte de divorcio entre la realidad jurídica y la realidad económica que exige velocidad, rapidez y fluidez en las transacciones contractuales.

Ferri destaca con gran precisión que "la moderna economía, caracterizada por la producción 'estandarizada' y en masa de bienes y servicios y el vasto consumo y comercio de ellos, ha favorecido la difusión de un tipo particular de negociación orientada a permitir la rapidez de la circulación de productos a través de la predisposición de esquemas contractuales uniformes y la consiguiente simplificación del iter contractual formativo del contrato"79.

En suma, la presencia de los contratos masivos dentro del tráfico masivo torna más ágil y fluido el intercambio patrimonial de bienes y servicios, y además permite reducir los costos de transacción para las partes contractuales. Así también lo ha señalado Soto Coaguila para quien la contratación masiva ha hallado su justificación al afirmarse que tiene por finalidad agilizar el tráfico patrimonial y reducir los costos de contratar o de transacción ${ }^{80}$.

De acuerdo al principio de rapidez contractual, la contratación masiva a través de los contratos por adhesión y de las cláusulas generales de contratación, tiene como función económica la de permitir no solo el intercambio o la asignación de bienes y servicios entre empresarios o proveedores hacia los consumidores a escala masiva, sino principalmente que tal intercambio se realice de la manera más rápida y con la mayor brevedad posible.

\subsection{El principio de economía contractual}

Este tercer principio que coadyuva en la función económica de la contratación masiva, como función específica que debe ser entendida en su sentido más

\footnotetext{
${ }_{78}$ Para Vallespinos lo ocurrido en las últimas décadas de nuestro siglo ha asumido tal particularidad que se distingue netamente de lo sucedido en otras etapas de la historia, en especial, por la constante movilidad y el agudo dinamismo que caracterizan nuestra sociedad. (VAllesPINOS, Carlos Gustavo; Op. Cit., p. 179).

79 Citado por De La Puente y Lavalle, Manuel. «El Contrato en general». Op. Cit., p. 688. En definitiva, lo que se busca con este sistema de contratación es viabilizar y agilizar la celebración de numerosos contratos, de forma tal que sin suprimir el consentimiento, pueda lograrse rápidamente el acuerdo contractual mediante la reducción de la negociación de las condiciones del contrato, siendo para ello necesario la predisposición del esquema contractual. (SOTO COAGUILA, Carlos Alberto. «La contratación contemporánea, el respeto a la autonomía privada y la protección de los contratantes débiles», Op. Cit., p. 69).

80 Soto CoAguila, Carlos Alberto. «La autonomía privada y la buena fe: fundamentos de la fuerza obligatoria del contrato». Op. Cit., p. 63.
} 
amplio y en relación con tres importantes factores: el tiempo, el dinero y el esfuerzo.

\subsubsection{El factor tiempo en la contratación masiva}

Este factor guarda directa relación con el principio de rapidez contractual. Las transacciones económicas actuales exigen el empleo de un mínimo indispensable de tiempo para celebrar un contrato masivo, ya que el empleo de un tiempo mayor al exigido por la dinámica del tráfico económico, conllevaría a la ineficiencia del contrato al resultar demasiado elevados los costos de transacción.

Hay que tener en cuenta lo indicado por Bullard: "En el mundo de hoy no hay lugar ni tiempo para largas negociaciones, en especial en mercados donde los propios productos y servicios están estandarizados" ${ }^{\prime \prime 1}$. Y, siendo una nota característica la "urgencia" en la contratación de un bien o servicio, la presencia de cualquier medio que signifique el ahorro de tiempo en la negociación, comporta al acelerado intercambio patrimonial.

De igual opinión es Rezzónico, cuando expone que el tiempo de conclusión del contrato se acorta cuando se evita en lo posible largas negociaciones entre las partes, repetitivas de un contrato a otro; basta que mediante la sola firma del cliente o su interiorización respecto del conjunto de cláusulas, para que se logre la disminución de costos fijos de conclusión ${ }^{82}$.

Por ello, mediante la presencia de los contratos por adhesión y de las cláusulas generales de contratación se pretende lograr una mayor "celeridad contractual", para que las partes o los potenciales contratantes, celebren un contrato con la mayor rapidez que les sea permitido, lo cual claro está, conlleva intrínsecamente al ahorro del tiempo que las partes previamente han calculado para la celebración de un contrato masivo, atendiendo a que actualmente lo que se busca es emplear el menor tiempo posible. Solo así, el contrato resultará un medio de intercambio eficiente para las partes ${ }^{83}$.

81 BulLARD GONZÁLES, Alfredo. «Firme primero, lea después! La contratación masiva y la defensa del consumidor». Op. Cit., p. 237. Montaigne considera que el Derecho, al ser dinámico por excelencia, frente a las exigencias de la "economía de tiempo" necesita de cierta flexibilidad, seguridad, rapidez y simplicidad. (Citado por: VAlLEspinos, Carlos Gustavo. Op. Cit., p. 235).

82 ReZzónico, Juan Carlos. Op. Cit., p. 183.

83 FERRI refiriéndose a la contratación masiva señala que "tal tipo de contratación que además se adecua también al rápido ritmo de la vida moderna, a la necesidad de 'no perder tiempo' común también al consumidor, el cual, si de un lado debe estar sujeto a una especie de 'diktat' del otro contratante, por otro lado está garantizado de ser las condiciones generales vinculantes para quien las ha ideado y predispuesto 


\subsubsection{El factor dinero en la contratación masiva}

El dinero es otro factor que determina la posibilidad de hacer viable la celebración de un contrato. Visto desde la perspectiva de la contratación masiva, el dinero no es sino un costo de transacción que en la mayoría de los casos resulta ser un elemento determinante en la conclusión del contrato.

Los contratos por adhesión y las cláusulas generales de contratación reducen estos gastos dinerarios que están presentes antes, durante y después de la celebración del contrato, permitiendo de esta manera que las partes contractuales puedan acceder al intercambio patrimonial, empleando al mínimo los recursos que se encuentren a su alcance. En igual sentido destacan los Stiglitz para quienes la contratación masiva constituye un mecanismo que al reducir la negociación, permite el consecuente ahorro de gastos concerniente a ambos contratantes ${ }^{84}$.

\subsubsection{El factor esfuerzo en la contratación masiva}

No cabe duda que este factor también importa costos de transacción. El despliegue importante de esfuerzos para celebrar un contrato puede resultar excesivo, insoportable para uno o para ambos contratantes y llevar a que se trunque toda contratación.

Aquí también juegan un rol fundamental los contratos por adhesión y las cláusulas generales de contratación que de alguna manera simplifican este conjunto de esfuerzos y los hacen accesibles, alcanzables para las partes. La forma como se materializa la reducción de los costos de transacción es mediante la limitación o la supresión de la negociación, que comúnmente es la etapa contractual donde las partes tienen que emplear mayores esfuerzos si es que desean contratar.

Lèauté confirma lo anotado al manifestar que los contratos tipo, ubicando entre ellos a las cláusulas generales de contratación, responden a una necesidad profunda del comercio contemporáneo, pues al reducir la duración de la fase precontractual, permiten seguir el ritmo cada vez más rápido de la vida de los negocios ${ }^{85}$.

\footnotetext{
y de asegurar con su aplicación uniforme, en orden al mismo tipo de relación, igualdad de tratamiento (FERRI, Luigi. Lecciones sobre el Contrato. Curso de Derecho Civil. Traducción de Nélvar Carreteros Torres. Lima: Editorial Grijley, 2004, p. 106).

84 Véase Stiglitz, Rubén S. y STiglitz, Gabriel A. Op. Cit., p. 20.

${ }^{85}$ Citado por ReZzónICO, Juan Carlos. Op. Cit., p., 183.
} 
Cabe anotar que es justamente en la reducción de esfuerzos, donde se encuentra el "Talón de Aquiles" de la contratación masiva. Esta forma contractual reduce a casi cero la capacidad de negociación de una de las partes contractuales, hecho que sin duda ha sido fuertemente debatido, por originar una suerte de desequilibrio contractual en una de las partes del contrato, la que ha tomado el nombre de "débil contractual".

Sin embargo, concordamos con Bullard cuando señala que "la paradoja es que para eliminar los costos de transacción se reduce la negociación que es, en la teoría tradicional del contrato, el mecanismo de garantía para que la autonomía privada exprese la libertad del individuo"86. Además, el autor citado afirma que el diseño contractual tradicional obedece a una idea de mercado artesanal, reducido y poco desarrollado. Hoy en día, este esquema es impensable; es necesario que se reduzcan los costos de transacción para que el mercado pueda funcionar como un adecuado asignador de recursos.

Debemos dejar postura de que el tema es muy cuestionable y seguirá siendo discutible, pues necesariamente conlleva a la necesidad de replantear el sistema contractual clásico desde las nuevas concepciones de la contratación masiva, propiamente consolidada en un sistema de contratación privada, cuya presencia hace más evidente y notoria las deficiencias del contrato tradicional. Su presencia es una realidad, que bien o mal, permite satisfacer una gran necesidad actual, alcanzar la rapidez que exige el tráfico contractual masivo, y además, en este camino permite reducir los costos de transacción que circundan la celebración de un contrato de naturaleza masiva, al punto que sean accesibles para las partes contractuales.

\subsection{El principio de simplificación contractual}

Indudablemente, este principio guarda estrecha relación con el principio comentado anteriormente, sobre todo en lo que concierne al factor esfuerzo, pero que sin embargo, dada su importancia, hemos creído conveniente darle un comentario particular ya que asocia una serie de factores que circundan el área de génesis y conformación de los contratos por adhesión y de las cláusulas generales de contratación.

Dejamos sentado que la contratación masiva, bajo las dos formas estudiadas, en términos generales reduce los costos de transacción existentes en el 86 Bullard GONZÁLES, Alfredo. «iFirme primero, lea después! La contratación masiva y la defensa del
consumidor». Op. Cit., p. 243. 
contrato, este efecto se refleja en el principio que hemos denominado simplificación contractual de la relación jurídica negocial, el cual comprende diversas ópticas, la del cliente o contraparte del contrato por adhesión o de las cláusulas generales de contratación, la de la empresa o industria y la perspectiva de ambos contratantes.

La simplificación es precedente a la celebración concreta del contrato por adhesión o del contrato con arreglo a cláusulas generales de contratación. El contrato clásico normalmente viene antecedido de un conjunto de tratos previos y negociaciones entre las partes que resultará finalmente, si todo sale bien, en la celebración del contrato. Pero estas tratativas preliminares, comportan una serie de costos de transacción, que tratándose de los contratos estudiados, pueden resultar impeditivos para concluir la celebración del contrato de manera eficiente. Pues, ni al oferente del contrato por adhesión o al predisponente de las cláusulas generales de contratación; ni al destinatario, cliente o consumidor que desean contratar por medio de estos contratos que resultan más expeditivos, les interesa identificarse, conocerse, entablar cierta amistad, ni realizar negociaciones ínter partes de contrato en contrato; esto es "inviable", tanto para quienes buscan proveerse "rápidamente" de bienes y servicios como para quienes tratan de colocarlos también rápidamente en el mercado.

En este caso, la labor de los contratos por adhesión y de las cláusulas generales de contratación es justamente la de simplificar estas cuestiones, para ahorrar tiempo, dinero y esfuerzos que se distribuyen a ambas partes. De esta manera, se reduce también el trecho entre quienes producen o proveen bienes y servicios y los consumidores o usuarios de los mismos.

En ambos contratos, se evita el inconveniente de tener que tratar con cada contratante, que de darse, puede conllevar a la existencia de una suerte de "carga contractual" que haga sumamente difícil la celebración de grandes cantidades de contratos masivos conforme lo exige el tráfico económico.

Asimismo, hablamos de simplificación porque la elaboración del contrato por adhesión y de las cláusulas generales de contratación queda al encargo de una sola de las partes, el oferente del contrato por adhesión o el predisponente de las cláusulas generales de contratación, quienes poseen los medios técnicos adecuados para ello. Y es más, tal elaboración previa, en muchos casos, es hecha con miras a uniformizar el contenido contractual de innumerables contratos a celebrarse en el futuro, lo que facilitará contratar con grandes grupos de personas. Deutch considera como beneficios de la estandarización 
de contratos los siguientes: a) Para el estipulante, los formularios a base de CGC (condiciones generales de la contratación) les resultan fáciles de elaborar, llenar y examinar, se evita la negociación de contratos numerosos y uniformes logrando el cálculo de riesgos y la exclusión de contingencias imprevistas, b) para el consumidor, la reducción de los costos de la empresa se reflejará en la reducción de costos, y al permitir los standard forms por su uniformidad y aplicación igualitaria evitan un examen al adherente, quien no siempre tendrá el tiempo ni el conocimiento para analizar en detalle tales contratos y, c) Para el tipo particular de comercio, por cuanto no se pueden prever todas las contingencias propias del negocio ${ }^{87}$.

Desde el punto de vista de la empresa o industria, este principio se halla en estrecha relación con la racionalización empresarial que conlleva a simplificar los términos contractuales, es decir, a estandarizar los contratos a fin de que mediante el ahorro de estos recursos se obtengan mayores beneficios. Y, su incorporación en el Derecho Contractual puede venir aunada al empleo de los contratos por adhesión o de las cláusulas generales, uniformizándolos para alcanzar aquella finalidad ${ }^{88}$.

La consecuencia de esta racionalización contractual puede significar un importante ahorro de recursos para la empresa y lo que a su vez puede significar para el cliente una reducción del costo de los bienes y servicios, así como en la facilidad que tendrá para contratar en base a un modelo ya predispuesto, no tendrá que negociar sólo declarar su conformidad, de modo que la adquisición de los bienes o el uso de determinados servicios se hace cada más expeditivo ${ }^{89}$.

Lo importante del asunto es que la simplificación contractual importa ventajas importantes para ambos potenciales contratantes que deben tenerse en cuenta. Por su lado, la empresa estandarizando los contratos por adhesión o a

87 Citado por Rezzónico, Juan Carlos. Ob. Cit., pp. 180 -181.

88 Diez PICAZO señala por ejemplo que las condiciones generales cumplen una función económica plausible, porque sólo uniformando el contenido contractual es posible una racionalización de las operaciones comerciales, que permita la contratación en masa con la consiguiente reducción de los costos y facilitación de las prestaciones". (DIEZ PICAZO, Luis. «Fundamentos de Derecho Civil Patrimonial». Op. Cit., pp. 367368).

89 Vallespinos alcanza al respecto que: "con la utilización de esta modalidad, las empresas, que en definitiva terminarán en ser los estipulantes de todas las relaciones contractuales contemporáneas, pueden realizar un estudio de costos y por ende de precios que les permitirá alcanzar un eficiente programa de producción. Además señala que la racionalización aplicada por las grandes empresas también ha seguido ese principio trasladándose al campo jurídico a fin de encontrar las técnicas apropiadas a esa directiva general. El resultado de esa búsqueda ha determinado que la contratación en base a condiciones generales sea la expresión jurídica más acorde para sus objetivos económicos (VALLESPINOS, Carlos Gustavo. Op. Cit., pp. 264-265). 
base de cláusulas generales de contratación, evita invertir una serie de costos para identificar y negociar con cada uno de sus contrapartes, previniendo los riesgos posibles y regulando las contingencias; mientras que los clientes o quienes en general decidan contratar en base a contratos por adhesión o por medio de contratos con arreglo a cláusulas generales de contratación, también evitan las arduas negociaciones que consumen tiempo, dinero y esfuerzos, adquiriendo con facilidad los bienes o servicios que necesiten.

\subsection{La función económica de la contratación masiva como fin en sí misma}

Al llegar a este punto, pretenderemos sustentar que la contratación masiva desde los presupuestos del AED, posee una función económica basada principalmente en lo que hemos denominado, la función de haberse constituido en "fin en sí misma".

Al concebir al contrato tradicional, no cabe ninguna duda que éste también posee una función económica que es la de "medio-fin". El contrato clásico es el medio, el instrumento más importante que permite a las partes contractuales lograr la satisfacción de sus necesidades e intereses, pues como ha sido establecido por nuestro ordenamiento civil, el contrato viabiliza un acuerdo con el objeto de crear, modificar, regular o extinguir relaciones jurídicas patrimoniales, alcanzado tal fin, el contrato paritario ha alcanzado su función económica trascendental al haber facilitado la concreción de las transacciones deseadas por las partes, canalizando el intercambio patrimonial de bienes y servicios.

Sin embargo, cuando abordamos los contratos masivos, específicamente los contratos por adhesión y las cláusulas generales de contratación, apreciamos que además de cumplir con la función de "medio-fin", manifiestan una función económica adicional y complementaria, la de ser "fin en sí mismos". Ello quiere decir que estos contratos masivos en comparación al contrato tradicional, ya no son meramente un canal o un medio para alcanzar determinadas aspiraciones económicas, sino que además estos mecanismos de contratación contemporánea, buscan que la satisfacción de determinadas necesidades e intereses de las partes sean materializados y concretizados de la manera más eficiente, eliminado toda complejidad en la celebración de innumerables contratos masivos y reduciendo al mínimo los costos de transacción en la celebración de un contrato, costos que para las partes, tratándose de la contratación masiva, serían en su mayoría sumamente onerosos e inalcanzables, y es más, aunque haya la posibilidad de alcanzar la configuración de tales contratos, éstos resultarían ineficientes para las partes. 
Indudablemente, ambas funciones, la de "medio-fin" y la "fin en sí misma", que interactúan en estas modalidades de la contratación masiva, tienen gran implicancia en el tráfico jurídico, en la fluidez que exigen las transacciones económicas actuales.

De allí que cobra vigencia la importancia de la función económica que viene cumpliendo la contratación masiva en el mercado, al haberse consolidado como el mecanismo más avanzado que ha elaborado el sistema contractual para hacer frente a una serie de fenómenos que se presentan bajo la característica de estandarizados, en masa y que muchas resultan ser factores impeditivos de la celebración eficiente de un contrato. Esto nos conduce a acoger la idea de Soto Coaguila expresada en los siguientes términos: "El derecho contractual debe estar diseñado por los legisladores de forma tal que contemple soluciones que no sólo reduzcan los costos de transacción, sino que además logren un mayor beneficio para las partes, generando un intercambio eficiente, un tráfico patrimonial seguro y eficaz que beneficie no sólo a las partes contratantes, sino también a la sociedad, puesto que un buen contrato evitará -o por lo menos las posibilidades serán mínimasconflictos futuros ${ }^{\prime \prime 90}$.

\section{CONCLUSIONES}

6.1. La contratación masiva constituye una respuesta de la capacidad de adaptabilidad del Derecho, específicamente del derecho contractual, ante los cambios científicos, tecnológicos, económicos y sociales que en su conjunto conforman la gran sociedad de masas, de manera que su aparición y regulación por el derecho civil se hace una cuestión necesaria.

6.2. La contratación masiva es una realidad, que permite satisfacer una gran necesidad, alcanzar la rapidez que exige el tráfico contractual masivo, y además, desde la perspectiva del análisis económico del derecho, permite reducir los costos de transacción que circundan la celebración de un contrato de naturaleza masiva, al punto tal que sean accesibles para las partes contractuales, logrando la satisfacción de sus necesidades e intereses.

6.3. Hemos considerado que la rapidez contractual, la eficiencia contractual, la economía contractual y la simplificación contractual son factores que nos pueden servir para configurar la función económica de la contratación masiva desde el análisis económico del derecho.

90 Soto CoAguila, Carlos Alberto. «La trasformación del contrato: Del contrato negociado al contrato predispuesto». Ob. Cit., p. 399. 
Reyler Yulfo Rodríguez Chávez - La función económica de la contratación masiva

6.4. La función económica de los contratos por adhesión y de las cláusulas generales de contratación a partir del análisis económico del derecho consiste en su capacidad para reducir los costos de transacción que circundan la celebración de un contrato de naturaleza masiva permitiendo que sean accesibles para las partes contractuales. Dicha función comprende a su vez dos elementos esenciales y constitutivos, la función de "medio fin", pues facilita la fluidez del tráfico económico creando, regulando, modificando y extinguiendo relaciones jurídicas patrimoniales, y la función de ser "fin en sí mismos", al ser los mecanismos más avanzados que ha elaborado el sistema contractual para dar mayor velocidad a las transacciones contractuales y reducir los costos de transacción presentes en estos contratos. 